\title{
The European Upper Mantle as Seen by Surface Waves
}

\section{Journal Article}

\section{Author(s):}

Boschi, Lapo; Fry, Bill; Ekström, Göran; Giardini, Domenico

Publication date:

2009

Permanent link:

https://doi.org/10.3929/ethz-b-000021325

\section{Rights / license:}

In Copyright - Non-Commercial Use Permitted

\section{Originally published in:}

Surveys in Geophysics 30(4-5), https://doi.org/10.1007/s10712-009-9066-2 


\title{
The European Upper Mantle as Seen by Surface Waves
}

\author{
Lapo Boschi · Bill Fry · Göran Ekström · Domenico Giardini
}

Received: 14 October 2008/Accepted: 15 March 2009/Published online: 23 April 2009

(C) Springer Science+Business Media B.V. 2009

\begin{abstract}
We derive a global, three-dimensional tomographic model of horizontally and vertically polarized shear velocities in the upper mantle. The model is based on a recently updated global database of Love- and Rayleigh-wave fundamental-mode phase-anomaly observations, with a good global coverage and a particularly dense coverage over Europe and the Mediterranean basin (broadband stations from the Swiss and German seismic networks). The model parameterization is accordingly finer within this region than over the rest of the globe. The large-scale, global structure of our model is very well correlated with that of earlier shear-velocity tomography models, based both on body- and surface-wave observations. At the regional scale, within the region of interest, correlation is complicated by the different resolution limits associated to different databases (surface waves, compressional waves, shear waves), and, accordingly, to different models; while a certain agreement appears to exist for what concerns the grand tectonic features in the area, heterogeneities of smaller scale are less robustly determined. Our new model is only one step towards the identification of a consensus model of European/Mediterranean uppermantle structure: on the basis of the findings discussed here, we expect that important improvements will soon result from the combination, in new tomographic inversions, of fundamental-mode phase-anomaly data like ours with observations of surface-wave overtones, of body-wave travel times, of ambient "noise", and by accounting for an a-priori model of crustal structure more highly resolved than the one employed here.
\end{abstract}

Keywords Seismic tomography $\cdot$ Surface waves $\cdot$ Upper mantle $\cdot$ Plate tectonics

\author{
L. Boschi $(\bowtie) \cdot$ B. Fry · D. Giardini \\ Institute of Geophysics, E.T.H., Zürich, Switzerland \\ e-mail: larryboschi@gmail.com \\ B. Fry \\ G.N.S. Science, Wellington, New Zealand \\ G. Ekström \\ Lamont-Doherty Earth Observatory, Columbia University, Palisades, NY, USA
}




\section{Introduction}

An effort is underway to identify a consensus model of seismic velocities under the Mediterranean Basin. From a strictly seismological point of view, advancing our knowledge of seismic structure in the area is an important step in the development of shakemaps, and in the accurate calculation of earthquake location, magnitude and geometry. The latter endeavour is also relevant in the context of the comprehensive nuclear test ban treaty, with the goal of improving the accuracy of algorithms used to determine the hypocenter and magnitude of seismic events. In the more general framework of Earth sciences, tomography can be seen as a tool to help explain tectonic displacements and lithospheric deformations, and ultimately understand the mechanisms that drive plate tectonics. Southern Europe, site of the Upper-Cretaceous closure of the Tethys ocean, of current ocean-continent collision at the Calabrian and Aegean arcs, and continent-continent collision elsewhere, is an especially interesting setting for analysing the works of tectonic forces. While plate motions in the region have been accurately reconstructed, the underlying dynamics are still debated (e.g., Faccenna et al. 2003; Capitanio and Goes 2006).

The present study is preceded by a number of competing tomographic models (Piromallo and Morelli 2003; Boschi et al. 2004; Marone et al. 2004; Pilidou et al. 2005; Kustowski et al. 2008a; Peter et al. 2008; Schmid et al. 2008; Weidle and Maupin 2008; Schivardi and Morelli 2009) and images (Bijwaard et al. 1998; Wortel and Spakman 2000), generally sharing the same macroscopic features: high velocities down to $\gtrsim 300 \mathrm{~km}$ under the East European Craton, and to even larger depths along a narrower band roughly corresponding to the Aegean Arc; low velocities in the top $\sim 100 \mathrm{~km}$ of the mantle under Anatolia and the Western Mediterranean, and, to a lesser extent, the Balkans and Germany. On the other hand, as we shall discuss in detail below (Sect. 10), the small-scale signature of models can differ significantly, to the point that their short-wavelength components are occasionally anti-correlated to one another. To some extent, differences in tomographic maps are a consequence of the properties of the sesimic observations used to derive them: it is more difficult to map small-scale features on the basis of low-frequency seismic signals. As a result, current surface-wave-based models can at best provide a low-passfiltered version of true seismic structure. Limitations in the coverage and quality of the data and in the theoretical formulation underlying tomographic inversions (ray-theory versus finite-frequency theory: Peter et al. 2008) and the arbitrarity inherent to the required tomographic regularization (e.g., Boschi and Dziewoński 1999) probably play an even more important role.

While recognizing that a consensus model of upper mantle structure should explain (and be derived from) body- as well as surface-wave observations, we focus here only on the latter, building on the work of Fry (2007) and Fry et al. (2008) to improve the relatively low-resolution model of Boschi et al. (2004). The latter authors could only count on the global Love- and Rayleigh-wave database of Ekström et al. (1997) and Boschi and Ekström (2002), with coverage over Europe not better than over other continental areas; Fry et al. (2008) conducted an important update of the database, via the analysis of seismic records from the Swiss and German permanent networks, as well as the temporary Midsea (van der Lee et al. 2001) and Tomo-CH (Fry 2007) deployments, as described in Sect. 2 below. This allowed, in turn, a commensurate refinement of model parameterization (Sect. 4), and we discuss in Sect. 5 the achieved effective resolution. The resulting new model of horizontally and vertically polarized shear velocities in the European upper mantle shares most of the features already mapped by Boschi et al. (2004), with some 
important differences. Relatively high-spatial-frequency anomalies particular to the new model are corroborated by independent seismic and/or geodynamic studies.

\section{New Observations of Love- and Rayleigh-Wave Phase Velocity}

Fry et al. (2008) measured phase-velocity dispersion of fundamental-mode Love and Rayleigh waves, at periods between 35 and $150 \mathrm{~s}$, on seismic recordings made in the years 1999-2006 at stations in the Midsea (van der Lee et al. 2001), SDSNet (Baer et al. 2000), TomoCH (Fry et al. 2008), and GRSN (Henger et al. 2002) networks (Fig. 1). Only recordings associated with events of magnitude $M_{w}>5.5$ and epicentral distances beteween $25^{\circ}$ and $150^{\circ}$ were considered, with the exception of a small number $(<1 \%$ of the total database) of regional events with epicentral distance $<25^{\circ}$.

Dispersion curves were derived through the algorithm of Ekström et al. (1997). Because the frequency-range over which a robust dispersion measurement is found varies depending on event and station, a data set of slightly different size corresponds to each type and period of surface wave. For Love-wave fundamental modes, the number of new observations grows, with growing period, from $\sim 4000(35 \mathrm{~s})$ to $\sim 6000$ (150 s); for Rayleigh waves at the same periods it varies between $\sim 9000$ and $\sim 12,000$.

We combine the new database with the one originally available to Boschi et al. (2004), including $\sim 25,000$ to $\sim 30,000$ Love-, and $\sim 50,000$ to $\sim 65,000$ Rayleigh-wave fundamental-mode phase-anomaly measurements between 35 and 150 s periods, and a smaller number of analogous, global measurements at longer periods (between $\sim 2000$ for Love waves at $300 \mathrm{~s}$, and $\sim 9000$ for Rayleigh waves at $200 \mathrm{~s}$ ). In an attempt to maximize the resolving power of the data, and in view of the larger available computer RAM and storage

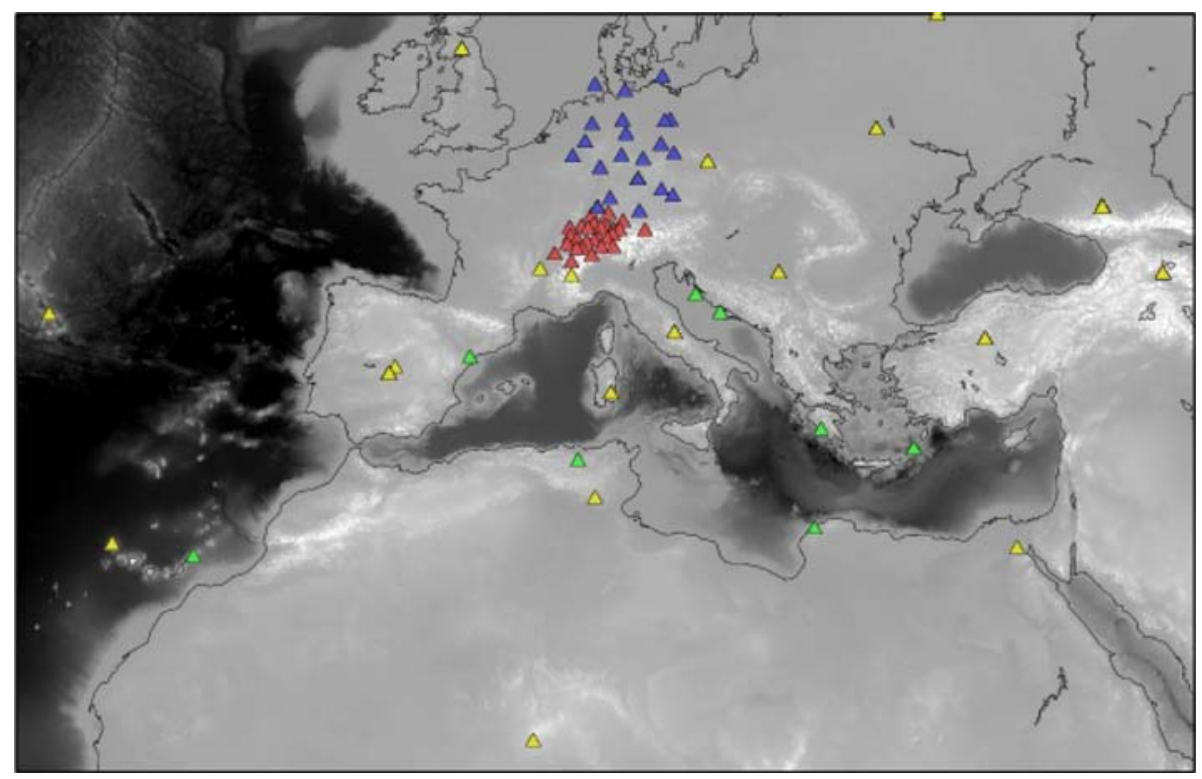

Fig. 1 We measured teleseismic surface-wave dispersion at stations from the Midsea (green triangles), SDSNet/TomoCH (red) and GRSN (blue) networks. Those measurements were combined with the dispersion database of Ekström et al. (1997) and Boschi and Ekström (2002) (yellow) 
space, we do not compute "summary rays" as in Boschi and Ekström (2002) and Boschi et al. (2004). In a set of preliminary tests on the original database of Boschi and Ekström (2002), we have verified that their summary-ray based results are reproduced almost exactly, if their procedure is repeated on the original, non-summary data.

Globally, the new database is $\sim 35 \%$ larger with respect to the one available to Boschi et al. (2004). Over most of continental Europe, the increase in data coverage ranges between $50 \%$ and $100 \%$, as illustrated in Fig. 3.1 of Fry (2007).

Combining measurements of different surface-wave modes, one notices that phase anomalies corresponding to higher frequency modes are systematically smaller than those associated with lower frequency ones. In our joint inversions of modes of different frequency, this effect might result in a systematic overfitting of higher frequency modes, with respect to the lower frequency ones. As explained in Sect. 4.1 of Boschi and Ekström (2002), we therefore assign to each phase-anomaly observation a weight, inversely proportional to the root-mean-square of all observations of the corresponding mode.

\section{Outline of the Theory}

We provide in this section a synopsis of our theoretical formulation, summarizing the treatment of Boschi and Ekström (2002) and Boschi et al. (2004).

\subsection{From Phase-Delay Data to Two-Dimensional Maps of Phase Slowness}

In the assumption that Earth's structure be smooth, at a frequency $\omega$ the phase delay $\delta \phi(\omega)$ associated with the corresponding Love- or Rayleigh-wave mode is linearly related to heterogeneities in the mode slowness $\delta p(\theta, \varphi ; \omega)$ through Fermat's principle

$$
\delta \phi(\omega)=\omega \int_{\text {ray path }} \delta p(\theta(s), \varphi(s) ; \omega) \mathrm{d} s
$$

(e.g., Ekström et al. 1997), with $\theta$ and $\varphi$ colatitude and longitude, respectively, and $\theta=\theta(s), \varphi=\varphi(s)$ the ray path equations. Equation 1 holds for each datum $\delta \phi_{m}$ $(m=1, \ldots, M)$ in the database, provided that the integration at its right hand side is conducted over the appropriate ray path, which we shall denote ray $\operatorname{path}_{m}$.

Let us now write the unknown heterogeneity $\delta p$ as the linear combination of a set of $I$ horizontal basis functions $S_{i}(\theta, \varphi)(i=1, \ldots, I)$,

$$
\delta p(\theta, \varphi ; \omega)=\sum_{i=1}^{I} x_{i} S_{i}(\theta, \varphi),
$$

with $x_{i}$ a set of $I$ unknown coefficients. After substituting $\delta p$ in (1) with its expression (2),

$$
\delta \phi_{m}(\omega)=\omega \sum_{i=1}^{I} x_{i} \int_{\text {ray }_{\text {path }}} S_{i}(\theta(s), \varphi(s)) \mathrm{d} s,
$$

and computing the integrals at the right-hand side of (3), 


$$
G_{m i}=\omega \int_{\text {ray } \operatorname{path}_{m}} S_{i}(\theta(s), \varphi(s)) \mathrm{d} s,
$$

a simple linear system is found, which can be written in tensor notation

$$
\delta \phi(\omega)=\mathbf{G} \cdot \mathbf{x},
$$

and must be solved to determine the coefficients $\mathbf{x}$ and a corresponding map of phaseslowness heterogeneity $\delta p$.

To reduce the effects of noise in the data, source location errors etc., seismic tomographers usually select $M \gg I$. Because of the nonuniformity in seismic data coverage, the resulting inverse problem (5) is not overdetermined, but mixed-determined, and can only be solved in least-squares sense.

\subsection{From Phase-Delay Data to Three-Dimensional Maps of Upper Mantle Structure}

Because we are interested in three-dimensional shear-velocity structure, we follow a different approach, making use of the equality

$$
\delta p(\theta, \varphi ; \omega)=\int_{0}^{a} \sum_{l=1}^{L} K_{l}(r, \theta, \varphi ; \omega) \delta v_{l}(r, \theta, \varphi) \mathrm{d} r
$$

(Boschi and Ekström 2002), based on local normal-mode theory (Tromp and Dahlen 1992), with $a$ denoting the Earth's radius, $\delta v_{l}$ the heterogeneities in a set of $L$ parameters describing the elastic properties of the Earth, and $K_{l}$ the corresponding sensitivity functions. After substituting (6) into (1),

$$
\delta \phi_{m}(\omega)=\omega \sum_{l=1}^{L} \int_{0}^{a} \int_{\text {ray }_{\text {path }}} K_{l}(r(s), \theta(s), \varphi(s) ; \omega) \delta v_{l}(r(s), \theta(s), \varphi(s)) \mathrm{d} r \mathrm{~d} s,
$$

$\delta v_{l}$ can be written, in analogy with Eq. 2, as a linear combination of $N=I \times J$ basis functions, each defined as the product of a horizontal basis function $S_{i}$ with a vertical one $R_{j}=R_{j}(r)$

$$
\delta v_{l}(r, \theta, \varphi)=\sum_{i=1}^{I} \sum_{j=1}^{J} x_{i j}^{l} S_{i}(\theta, \varphi) R_{j}(r),
$$

and substituting (8) into (7),

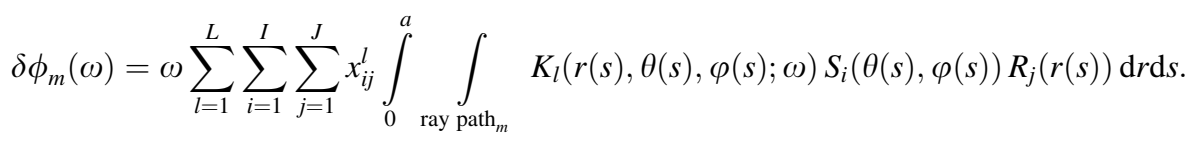

(Boschi and Ekström 2002).

Let us establish a one-to-one correspondence between the index couples $i j$ and a single index $n=1, \ldots, N$. We can then define 


$$
A_{m n}^{l}=\omega \int_{0}^{a} \int_{\text {ray path }_{m}} K_{l}(r(s), \theta(s), \varphi(s) ; \omega) S_{i}(\theta(s), \varphi(s)) R_{j}(r(s)) \mathrm{d} r \mathrm{~d} s,
$$

and Eq. 9 collapses to

$$
\delta \phi_{m}(\omega)=\sum_{l=1}^{L} A_{m n}^{l} x_{i j}^{l} .
$$

Introducing a matrix $\mathbf{A}$ and vector $\mathbf{x}$ comprised, respectively, of all matrices $\mathbf{A}^{1}, \mathbf{A}^{2}$, hellip;, $\mathbf{A}^{L}$, and of all vectors $\mathbf{x}^{1}, \mathbf{x}^{2}, \ldots, \mathbf{x}^{L}$ combined in a consecutive manner, the usual tensorial form is found for Eq. 11,

$$
\delta \phi(\omega)=\mathbf{A} \cdot \mathbf{x} .
$$

Our inversions, discussed below, consist of solving (12) in damped least-squares sense (for the reasons outlined at the end of Sect. 1), i.e.

$$
\mathbf{x}=\left(\mathbf{A}^{T} \cdot \mathbf{A}+\mathbf{D}\right)^{-1} \cdot \mathbf{A}^{T} \cdot \delta \phi,
$$

where the superscript $T$ denotes matrix transposition, the superscript -1 matrix inversion, and $\mathbf{D}$ the regularization or damping matrix (Boschi et al. 2004).

In analogy with Boschi and Ekström (2002) we select $L=2$, the only free parameters of our inversions being horizontally and vertically polarized shear velocities.

\section{Model Parameterization}

We apply the algorithm of Boschi et al. (2004) to translate phase anomaly data into a threedimensional map of horizontally and vertically polarized, shear and compressional velocities. Following Boschi and Ekström (2002), we assume heterogeneities in horizontally and vertically polarized compressional velocities to coincide with heterogeneities in horizontally and vertically polarized shear velocities, respectively.

In agreement with the multiple-resolution philosophy of, e.g., Bijwaard et al. (1998), we parameterize the whole globe, with a grid of local basis functions that becomes finer in the region that is best covered by the data. This way, smearing of global heterogeneity into the localized region to be mapped is minimized, while the number of free parameters remains relatively small, limiting computational costs. Unlike Bijwaard et al. (1998), we do not design an "adaptive" grid, with locally variable density proportional to local data coverage, but more simply choose one region of interest, where we replace the coarse global grid with a much finer one. More specifically, we apply the algorithm of Wang and Dahlen (1995) to define a cubic B-spline basis on a triangular grid of knots with approximately constant inter-knot spacing. We first conduct a 6-fold tessellation (Wang and Dahlen 1995), to establish the global parameterization knots. Splines associated with knots of longitude between $10^{\circ} \mathrm{W}$ and $30^{\circ} \mathrm{E}$, and latitude between $30^{\circ} \mathrm{N}$ and $60^{\circ} \mathrm{N}$, are excluded from the final parameterization. A 30 -fold tessellation defines the more closely spaced knots to be used locally. Of the splines resulting from this finer tessellation, only the ones whose knots fall within the region defined above are included in the final parameterization, illustrated in Fig. 2b. The high-resolution area is approximately centered on Switzerland, where station density is highest. Comparison of Fig. 2a with b illustrates the refinement of 

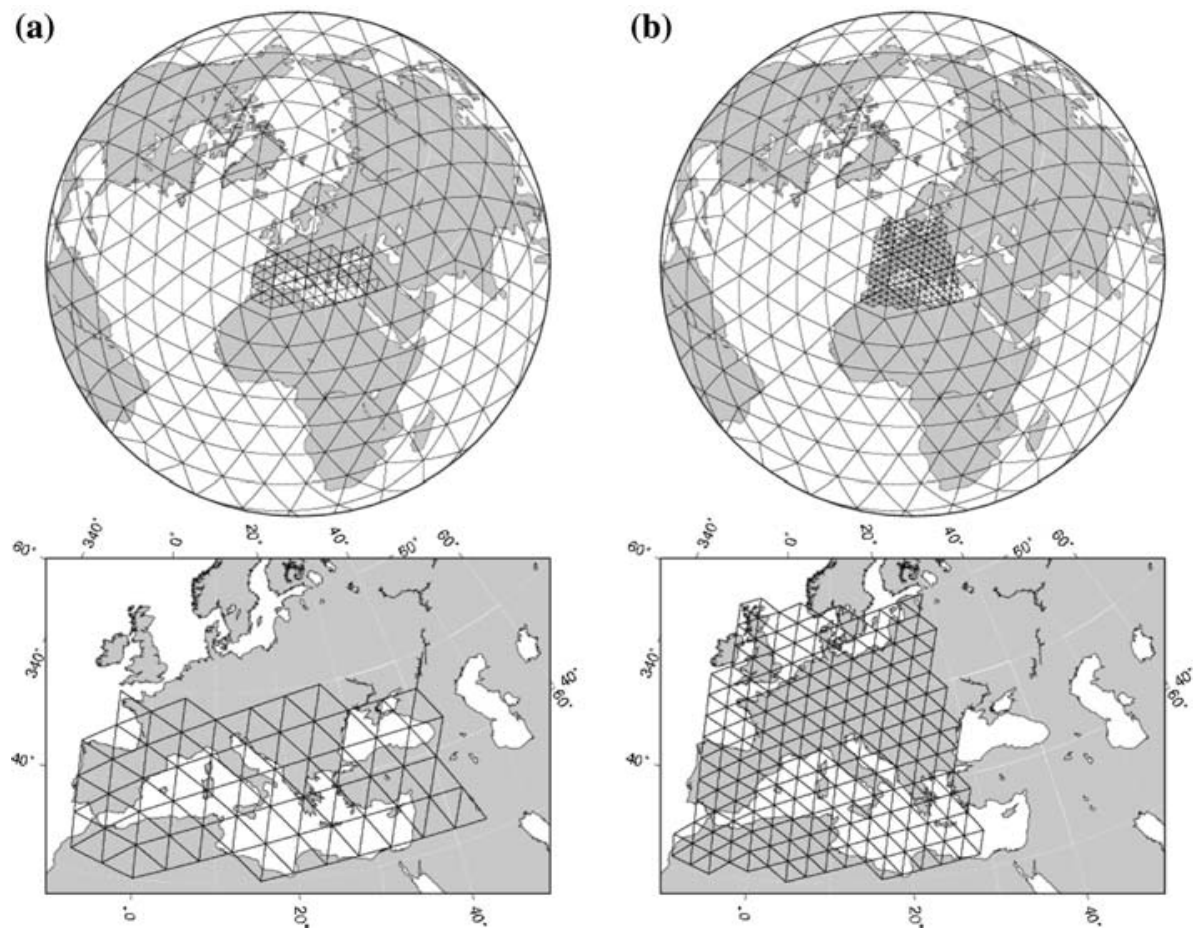

Fig. 2 (a) Spline-knots in the parameterization of Boschi et al. (2004), and (b) this study. The top panels show the multiple-resolution parameterization that was actually employed; the bottom panels show only the knots of the more closely-spaced splines within the high-resolution regions

parameterization with respect to the work of Boschi et al. (2004): from 66 to 183 splines in the high-resolution region. The rest of the globe is described by 355 splines, so that our horizontal parameterization involves 538 splines total. The vertical parameterization is the same as that of Boschi et al. (2004), illustrated in their Fig. 1a. It consists of 9 cubic splines centered at $60 \mathrm{~km}$-spaced knots between 0 and $300 \mathrm{~km}$ depth, and $150 \mathrm{~km}$-space knots between 300 and $450 \mathrm{~km}$. As horizontally and vertically polarized shear velocities are parameterized independently, each of our models consists of 9684 coefficients.

\section{Tomography Resolution}

The resolution of seismic tomography is limited by a number of factors, including data coverage, data quality, and the accuracy of the theoretical formulation of the inverse problem, which generally involves some important approximations.

\subsection{Data Quality}

The observational uncertainties associated with the dispersion-measuring algorithm employed here were determined empirically by Ekström et al. (1997), who essentially compared phase-anomaly measurements from nearby paths. Low-frequency seismic observations associated with nearby paths sample approximately the same structure, and 
should accordingly be approximately coincident: discrepancies can be used to estimate measurement errors. The results of this exercise are summarized in Table 2 of Ekström et al. (1997), as a function of period and for both Love and Rayleigh waves.

Ekström et al. (1997) note that their uncertainty estimate is "likely to be smaller than the true uncertainty, since it does not include the effects of systematic errors, for example, in earthquake locations." The opposite could also be true, however, as, in the presence of crustal anomalies of small spatial wavelength but large amplitude, differences between phase-anomalies recorded at nearby paths might not reflect a measurement error, but rather be the physically meaningful results of nonlinear effects in wave propagation.

With some preliminary experiments, we have verified that inversion of the data obtained from the Midsea, Tomo-CH, SDS-Net and GRSN arrays and networks only provides global phase-velocity maps consistent with those of Ekström et al. (1997), with increasing, but surprisingly limited smearing as the distance from Europe increases. We have also mentioned above that the phase velocity maps we find do not change much, whether or not we combine the data in summary "bundles" before inversion. These are additional indications of the high reliability of our data.

\subsection{Data Coverage: A "Checkerboard" Test}

In a 3-D tomography exercise based on the inversion of surface-wave data, coverage is defined not only by the density with which seismic sources and stations are distributed over and around the region to be mapped, but also by the physics of surface-wave sensitivity to structure at depth. In our infinite-frequency approximation, local sensitivity functions can be defined that relate a phase-velocity estimate at a given location to the vertical profile of shear velocity (and, to a lesser extent, density and compressional velocity) at the same location; the form of such "Fréchet derivatives", or "sensitivity kernels", depends on the local assumed a priori structure: the starting model (Tromp and Dahlen 1992; Boschi and Ekström 2002). An example is shown in Fig. 3. As a general rule, waves of longer period are sensitive to deeper structure. At any given period, the Rayleigh wave samples deeper than the Love wave. The large width of the depth-range that surface waves are sensitive to should immediately suggest the difficulty of accurately constraining sharp vertical changes in Earth's structure. The fact that this width grows with increasing period anticipates that resolution decreases with depth, and that the transition zone is not really sampled, at this stage, by our data.

To quantify these resolution limits, together with the less severe ones imposed by the nonuniformity of source and station distributions, we compute the model resolution matrix $\mathbf{R}$ associated with the entire database, as described by Boschi et al. (2004). What used to be considered an impossibly expensive computation, can now be completed in a matter of minutes on a standard desktop computer, via a Cholesky factorization (e.g., Trefethen and Bau 1997) of $\mathbf{A}^{T} \cdot \mathbf{A}+\mathbf{D}$ introduced in Eq. 13. We implement Cholesky factorization by means of single-precision, sequential $L A P A C K$ routines. Naturally, the regularization $\mathbf{D}$ imposed at this point coincides with that applied to the inversions that lead to our favoured solution models (Sects. 6, 7). Once $\mathbf{R}$ is known, we can quickly dot-multiply it with any given "input" model: the similarity between the result (the "output" model) and the input model itself is a measure of resolution. This measure has the important drawback of depending on our choice of the input model, so that an absolute estimate of resolution is impossible: in earlier studies we visualized R as a whole (Boschi 2003; Boschi et al. 2004). Here we opt for a less rigorous approach, whose results are however more easily interpretable. 

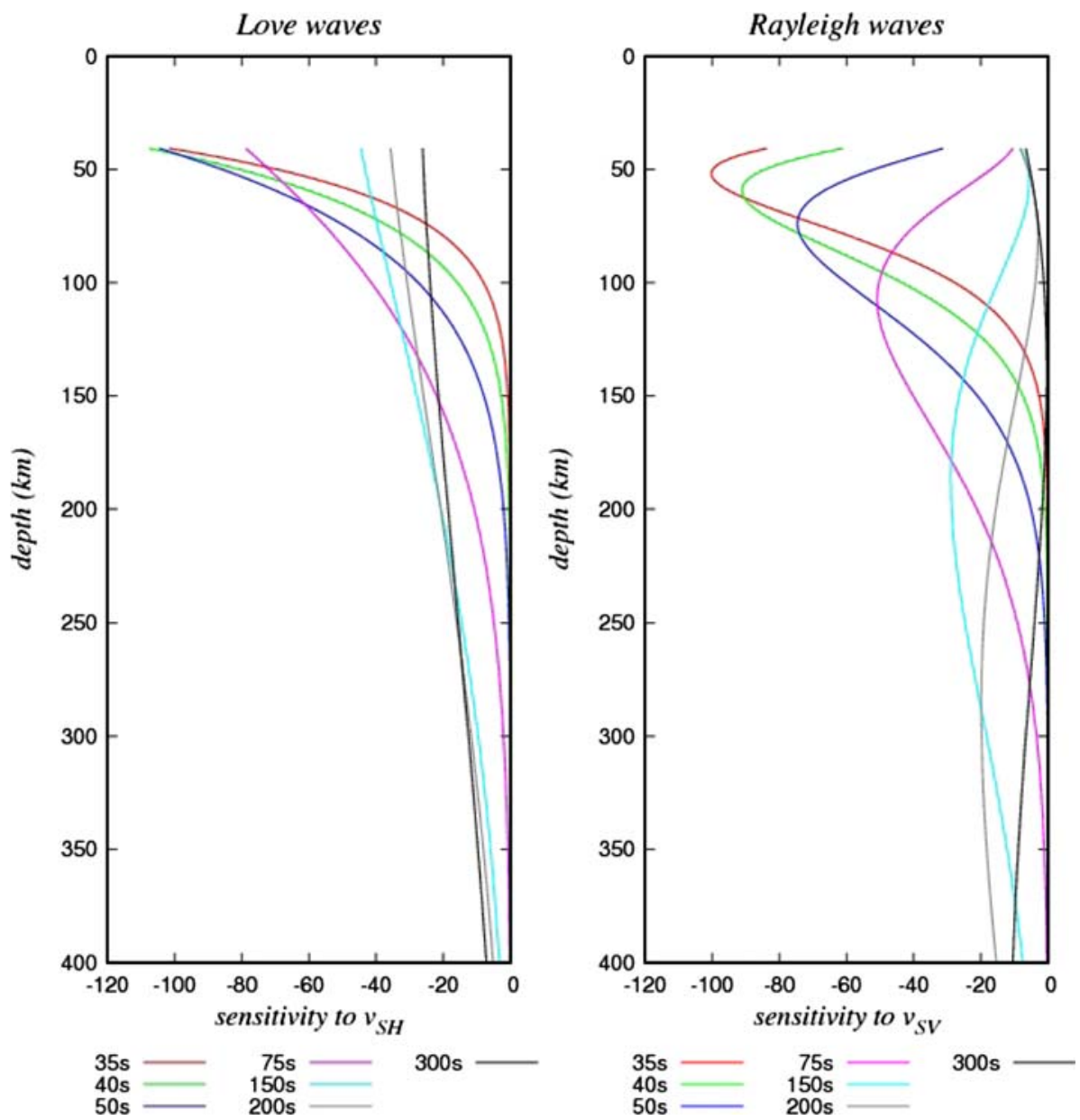

Fig. 3 Sensitivity kernels relating Love- (left) and Rayleigh-wave (right) phase-anomaly observations made at different periods (colors), with horizontally polarized and vertically polarized shear-velocity heterogeneities at various upper-mantle depths (vertical axis). The data are preliminary corrected for an assumed crustal model, and sensitivity to structure above the Moho is accordingly set to zero

Our input "checkerboard" models consist of a spherical harmonic function of selected degree and order in the high-resolution region, and a null model over the rest of the globe. The sign of the input model is switched at several selected depths. This model is first projected onto a regular longitude-latitude-depth grid; the spline-coefficients corresponding to our parameterization (Sect. 4) are then found via a least-squares fit implemented, again, by Cholesky factorization. As anticipated, the output model then coincides with the dot-product of $\mathbf{R}$ and the vector of spline coefficients thus found. By construction, the input model is relatively smooth and can be represented by our parameterization.

The input model corresponding to the degree 42, order 21 normalitzed harmonic, and changes in sign at 200 and $500 \mathrm{~km}$ depth, is compared in Figs. 4, 5 and 6 with the corresponding output model. 

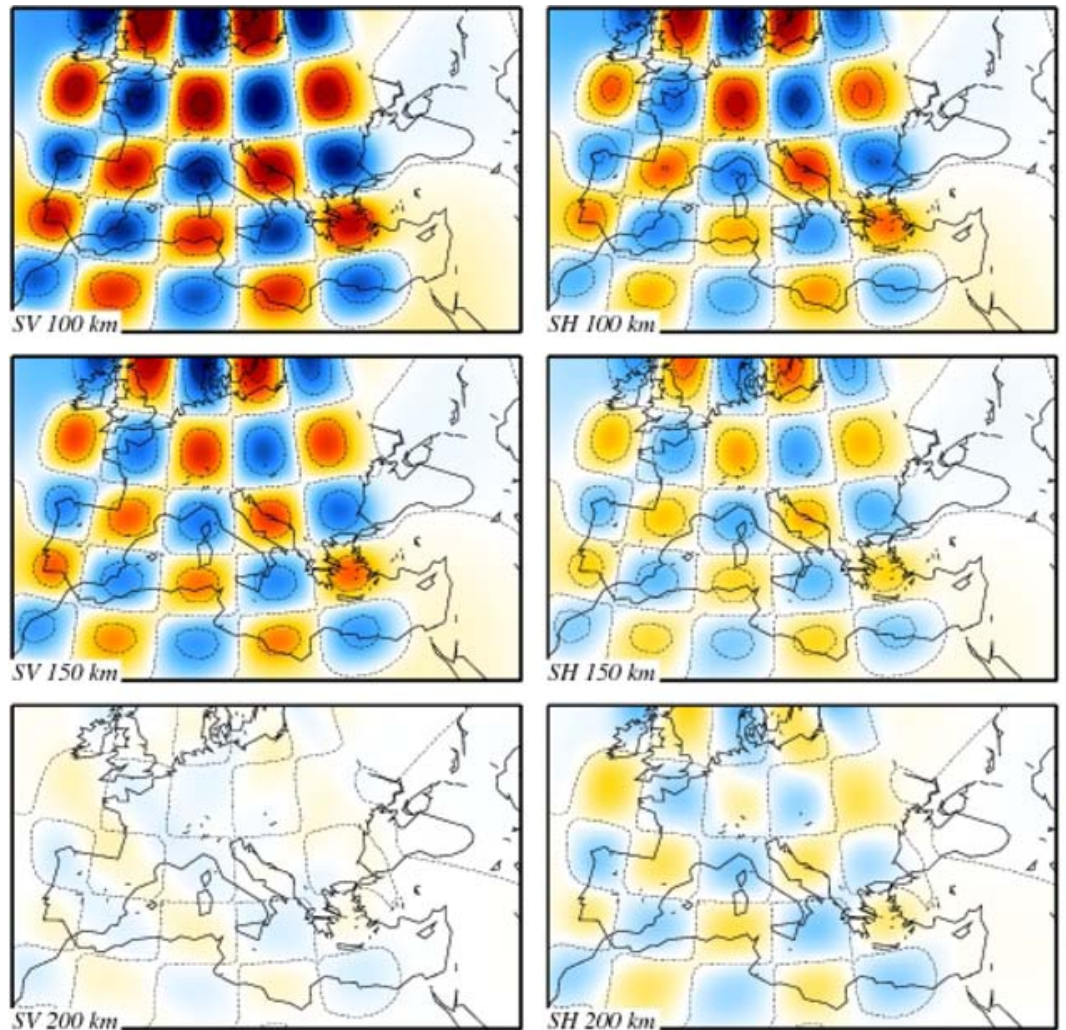

0.500

0.375

0.250

SV $200 \mathrm{~km}$

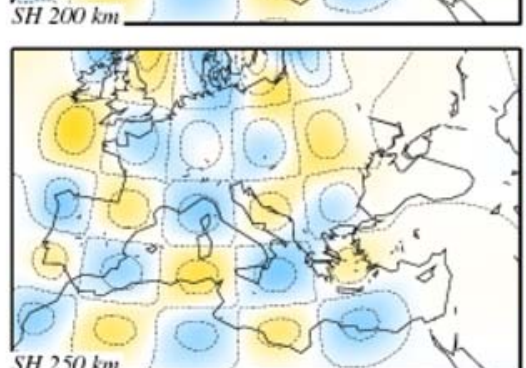

0.125

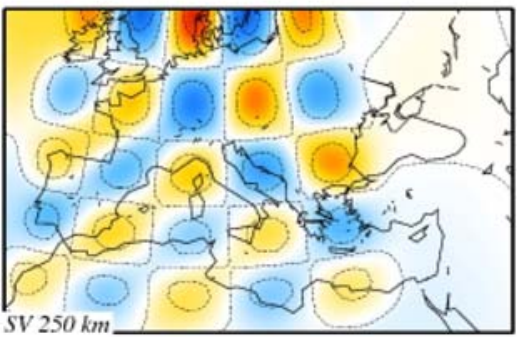

SH $250 \mathrm{~km}$

0.000

Fig. 4 Input (contour lines) and output (colors) models from the checkerboard test described in Sect. 2, horizontal sections of (left) $\delta v_{S V} / v_{S V}$ and (right) $\delta v_{S H} / v_{S H}$, at (top to bottom) 100, 150, 200 and $250 \mathrm{~km}$ depth

The left panels of Fig. 4 show that, at this level of complexity, the horizontal pattern of vertically polarized shear-velocity heterogeneities $\delta v_{S V}$ is resolved well by the available data. The change in sign of the input model at $200 \mathrm{~km}$ depth is also reproduced well so far as $\delta v_{S V}$ is concerned. The input-model $\delta v_{S V}$ amplitude is reproduced accurately in the top $\sim 200 \mathrm{~km}$, but is increasingly underestimated with increasing depth.

The right panels of Fig. 4 show that the pattern of horizontally polarized shear-velocity heterogeneities $\delta v_{S H}$ is well resolved only within the top $\sim 150 \mathrm{~km}$ of the mantle. At larger depths, maps of $\delta v_{S H}$ are dominated by vertical smearing. Since $\delta v_{S H}$ is almost exclusively constrained by Love-wave data, this effect can be ascribed to the physics of Love- versus 
Rayleigh-wave propagation, as summarized in Fig. 3: Love-wave sensitivity kernels all decrease monotonously with increasing depth, and are generally quite close to zero (especially for periods of $150 \mathrm{~s}$ and shorter, at which most measurements were made) at depths $\gtrsim 150 \mathrm{~km}$, where $\delta v_{S H}$ is consequently not resolved.

The vertical sections in Fig. 5 additionally show that the sharp gradient in $\delta v_{S V}$ at $200 \mathrm{~km}$ is well resolved; the one at $500 \mathrm{~km}$ is partly resolved, with some vertical smearing. Input and output sections of $\delta v_{S H}$ in Fig. 6 are less well correlated to one another, showing that sharp vertical gradients in $\delta v_{S H}$ cannot be resolved by our data.

\subsection{The Ray-Theory Limit}

The present study is an application of the algorithm of Boschi et al. (2004), which is based on the ray-theory, infinite-frequency approximation: one can then infer a physical resolution limit for the models that we derive, coinciding with (or close to) the wavelength of the inverted seismic observations (Peter et al. 2009). At the shortest periods considered here, the highest possible resolution should then be $\sim 200 \mathrm{~km}$.

It remains unclear to what extent this limit can be outdone through the application of finite-frequency methods (Li and Romanowicz 1996; Dahlen et al. 2000; Spetzler et al. 2001; Zhou et al. 2006). Peter et al. (2008) compared ray-theoretical and finite-frequency tomographies based on the Rayleigh-wave component of our database. As anticipated by Fry et al. (2008), the two approaches provide quite similar results at most frequencies; only the $150 \mathrm{~s}$ phase-velocity maps derived from ray- versus finite-frequency theory differ significantly. As a general rule, the depth range where sensitivity is highest grows with increasing period (Fig. 3); $150 \mathrm{~s}$ Rayleigh waves are, e.g., mostly sensitive to structure at $\sim 200 \mathrm{~km}$ depth. Shallower structure is well constrained by shorter-period observations. We infer that, at the spatial wavelengths that we are trying to resolve, finite-frequency effects are only an issue for relatively large depths. We expect that it will become necessary to take them into account, when surface- and body-wave data are combined in efforts to map the entire upper mantle, at increasingly high resolution.

\section{First Iteration Model}

We define a starting model which coincides with PREM (Dziewoński and Anderson 1981) at depths $\geq 220 \mathrm{~km}$; above this depth, all parameters vary linearly with slopes equal to those between 400 and $220 \mathrm{~km}$ depth: in contrast to PREM, our starting model is entirely isotropic and has no $220 \mathrm{~km}$-discontinuity. Surface topography, crustal structure, and depth of the Moho discontinuity change laterally as in model Crust2.0 of Bassin et al. (2000). Boschi et al. (2004) employed this very starting model, updating the crustal portion of the model of Boschi and Ekström (2002), who were still limited to Crust5.1 (Mooney et al. 1998).

We express phase delays in our database as anomalies with respect to the phase predicted by our starting model. For each pixel of Crust2.0, we compute the corresponding local Love- and Rayleigh-wave sensitivity kernels $K_{l}(r, \theta, \varphi ; \omega)$, introduced in Sect. 2. We implement Eq. 10, to set up an inverse problem of the form (13) whose unknowns are the spline coefficients of relative $\delta v_{S H} / v_{S H}$ and $\delta v_{S V} / v_{S V}$ heterogeneity throughout the upper mantle. Crustal structure is left unperturbed.

We next conduct a number of least-squares inversions, implemented, again, via Cholesky factorization of $\mathbf{A}^{T} \cdot \mathbf{A}+\mathbf{D}$. The regularization matrix $\mathbf{D}$ is the product of the 

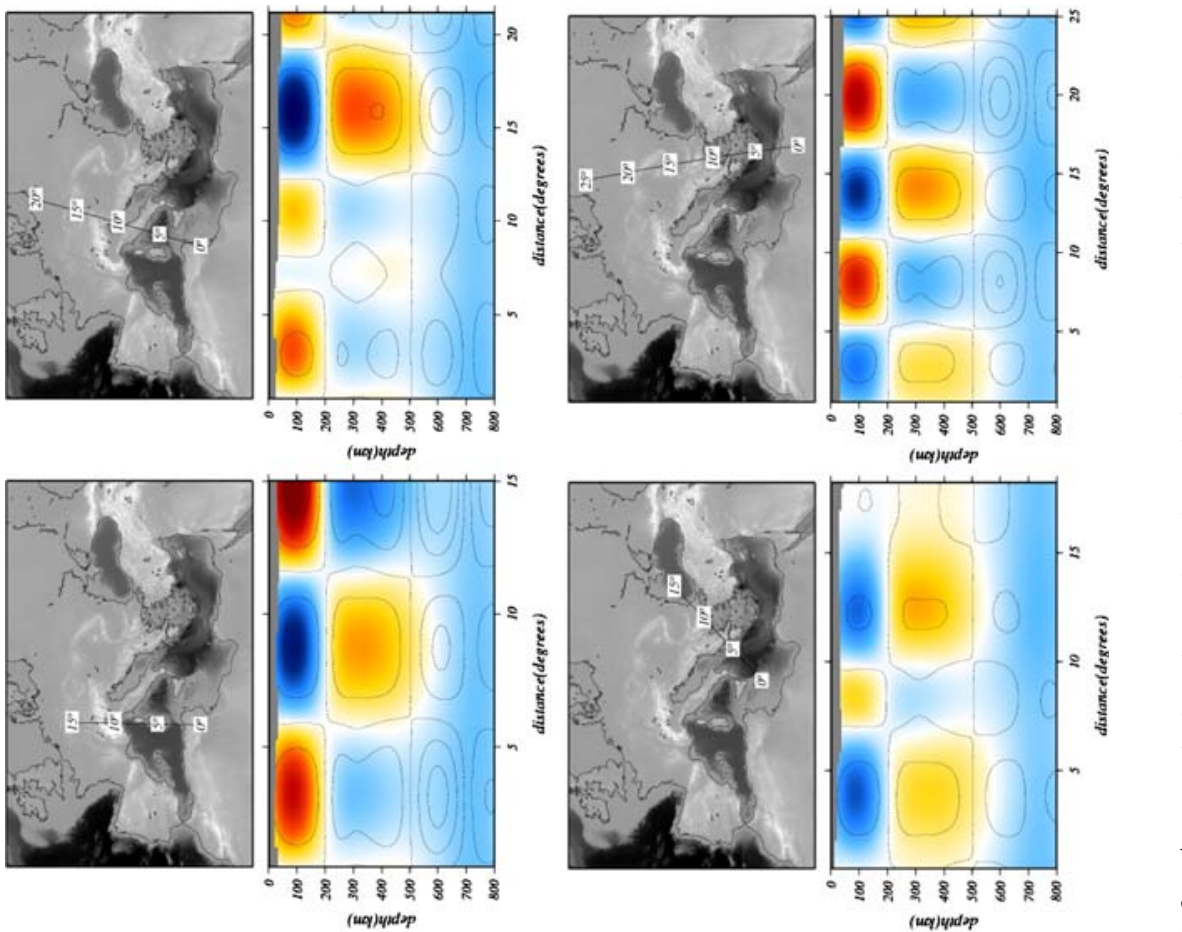

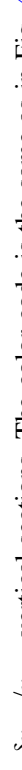
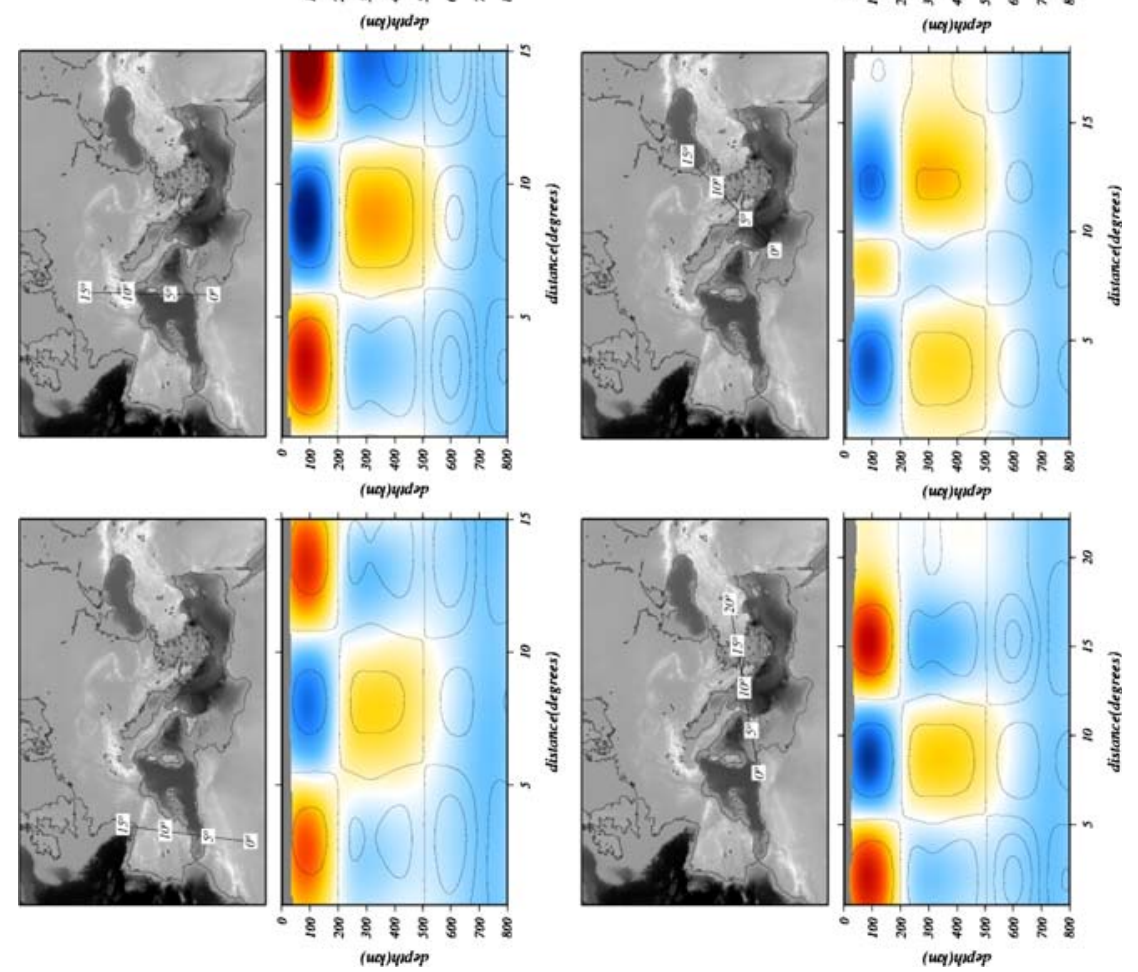

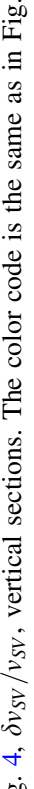

穴

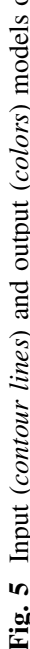



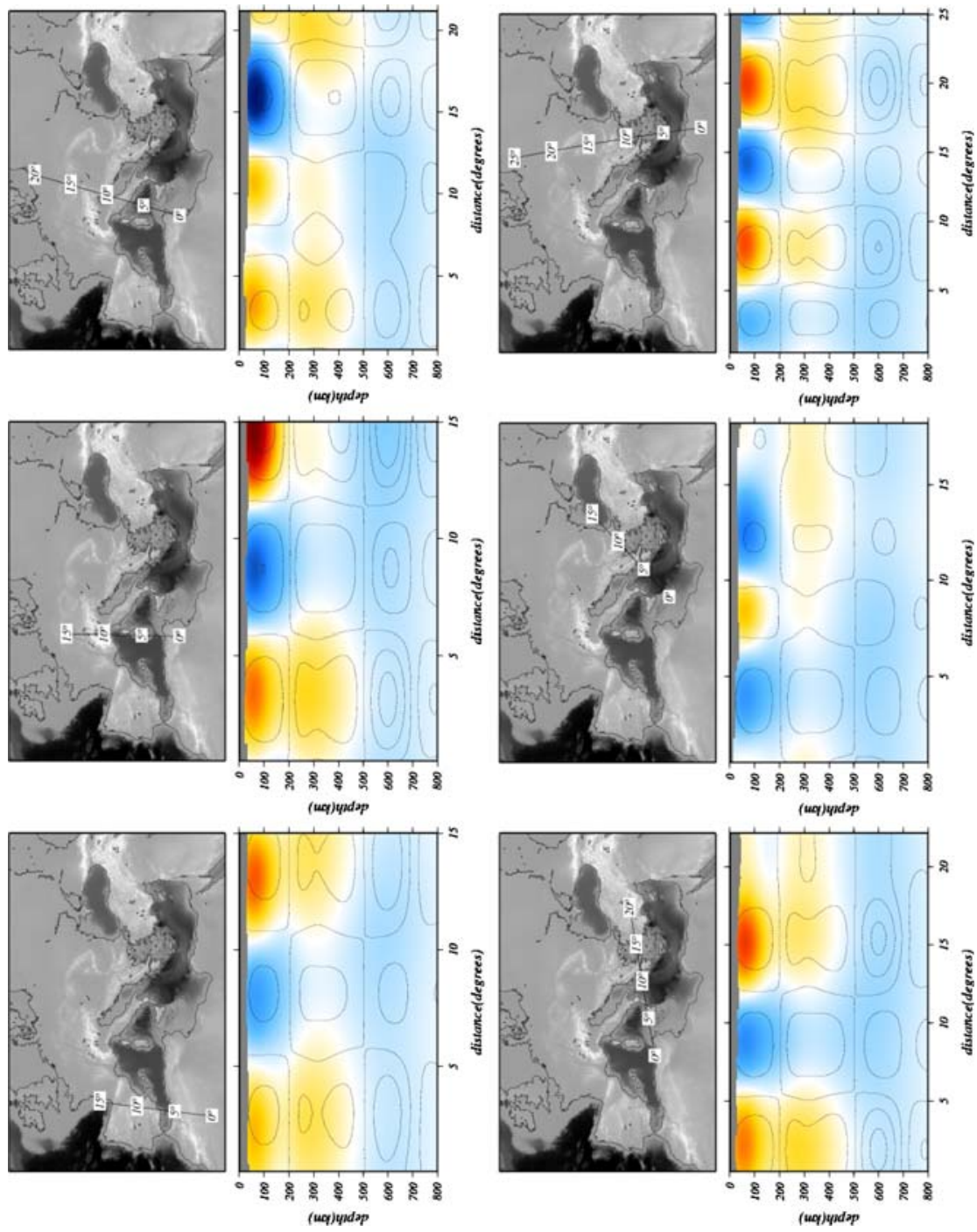

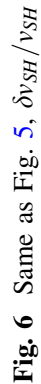


identity matrix and a scalar constant (the "damping parameter") that we vary at each inversion. Clearly, the strength of regularization is proportional to the scalar constant. This regularization scheme is approximately equivalent to simple "norm damping" (Boschi and Dziewoński 1999). We prefer to minimize the norm, rather than the roughness of the solution, because our spline parameterization naturally provides relatively smooth solutions, and our goal here is to resolve fine structure.

Our preferred first-iteration model (shown in Figs. 7 through 9 and hereafter dubbed LRSP3OEU1) is selected qualitatively on the basis of the L-curve criterion (Hansen 1992): models more complicated than LRSP3OEU1 do not improve data-fit much, while simpler ones quickly deteriorate it. Data-fit remains, however, approximately constant over a relatively wide range of solutions: among those, LRSP3OEU1 is the one that appears to best recover some expected tectonic features. See, for example, a narrow fast region underlying the western coast of Italy, partly associated with subduction at the Calabrian arc (Fig. 8). This feature, expected on the basis of tectonic reconstructions (Wortel and Spakman 2000; Faccenna et al. 2003; Capitanio and Goes 2006), was mapped in other tomographic inversions, but could not be resolved by Boschi et al. (2004) (Sect. 10).

\section{Second Iteration Model}

Because the sensitivity of a surface wave to local structure at depth depends on the structure itself (e.g., Tromp and Dahlen 1992), the problem that we are solving is inherently nonlinear, even within the ray-theory approximation. We accomodate the nonlinearity with an iterative approach, employing LRSP3OEU1 as the starting model of a new inversion (Boschi and Ekström 2002). In practice, we project LRSP30EU1 onto the $2^{\circ} \times$ $2^{\circ}$ pixel grid of Crust2.0, and compute, at each pixel, the Love- and Rayleigh-wave sensitivity kernels associated with combined local crust and mantle structure. We then implement and solve a new inverse problem, whose unknowns are $\delta v_{S H} / v_{S H}$ and $\delta v_{S V} / v_{S V}$ relative to LRSP3OEU1. We apply the same regularization scheme as above, and vary the value of the damping parameter to find, again, a family of possible solutions. Perturbations to LRSP3OEU1 are generally small, and limited to the amplitude (rather than pattern) of velocity anomalies. We select as our preferred 2nd-iteration model (LRSP3OEU2 hereafter) the one associated with the same damping-parameter value that lead to LRSP3OEU1. LRSP3OEU1 and LRSP3OEU2 are similar enough that we do not believe any further iteration to be necessary.

We transform the distributions $\delta v_{S H} / v_{S H}$ and $\delta v_{S V} / v_{S V}$ of LRSP3OEU2 to perturbations with respect to our initial starting model, and plot them in Figs. 9 through 12. Figures 10 and 11 can be directly compared to Figs. 7 and 8, as velocity anomalies are referred to the same model.

The mean values of $v_{S H}$ and $v_{S V}$ from LRSP3OEU2 (or LRSP3OEU1) as a function of depth (Fig. 9a) confirm earlier findings by Ekström and Dziewoński (1998), Boschi and Ekström (2002) and Boschi et al. (2004): radial anisotropy in shear velocity is similar in magnitude to that of PREM, but extends to larger depths; no global $\sim 220 \mathrm{~km}$ discontinuity is required by our data. In the European/Mediterranean upper mantle (Fig. 9b) velocities are systematically higher, particularly at shallow depths, which reflects the large thickness of continental lithosphere. Anisotropy is, again, comparable with that of PREM. Even in this continental area, there is no requirement of a $\sim 220 \mathrm{~km}$ discontinuity to explain the data. 


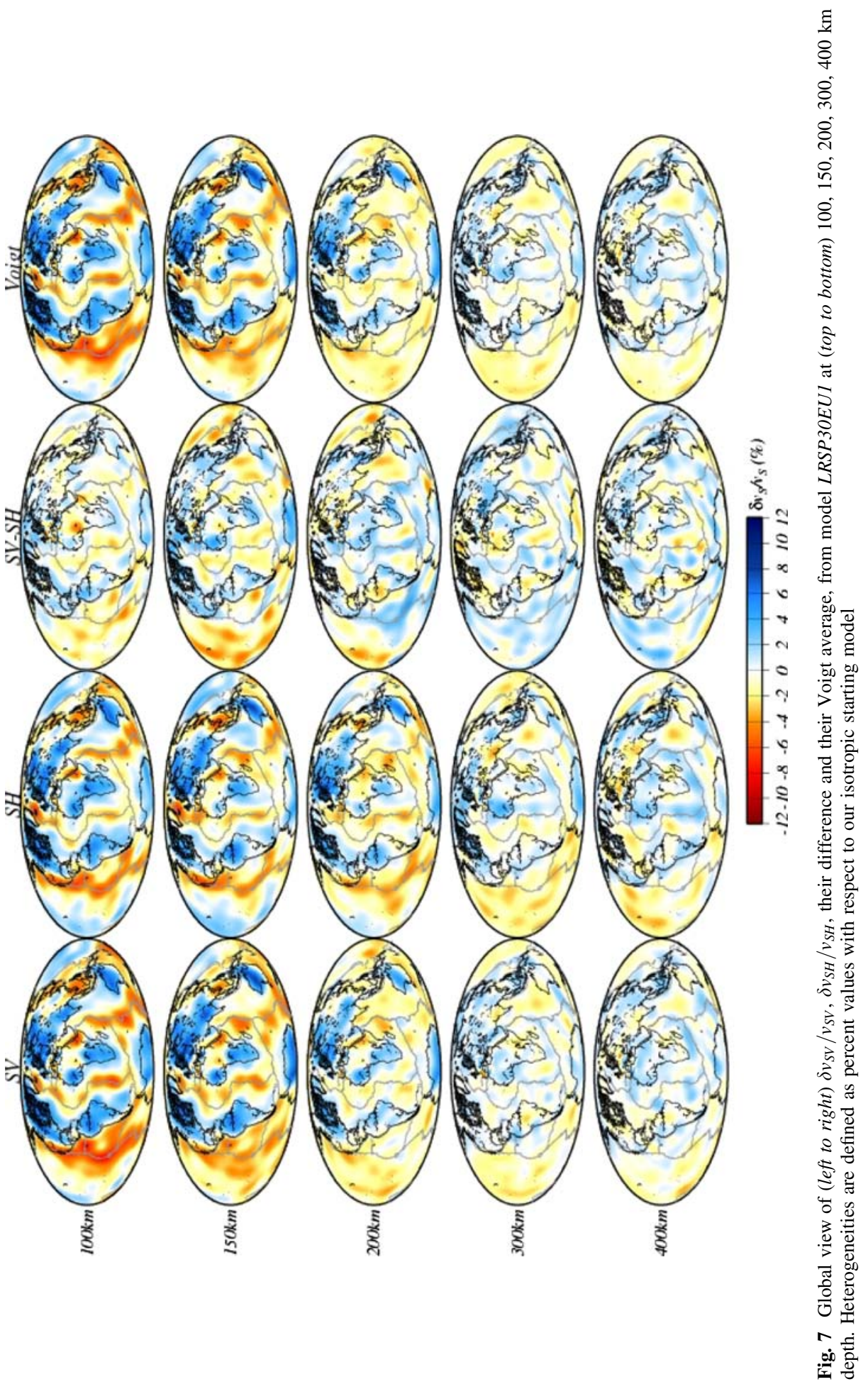



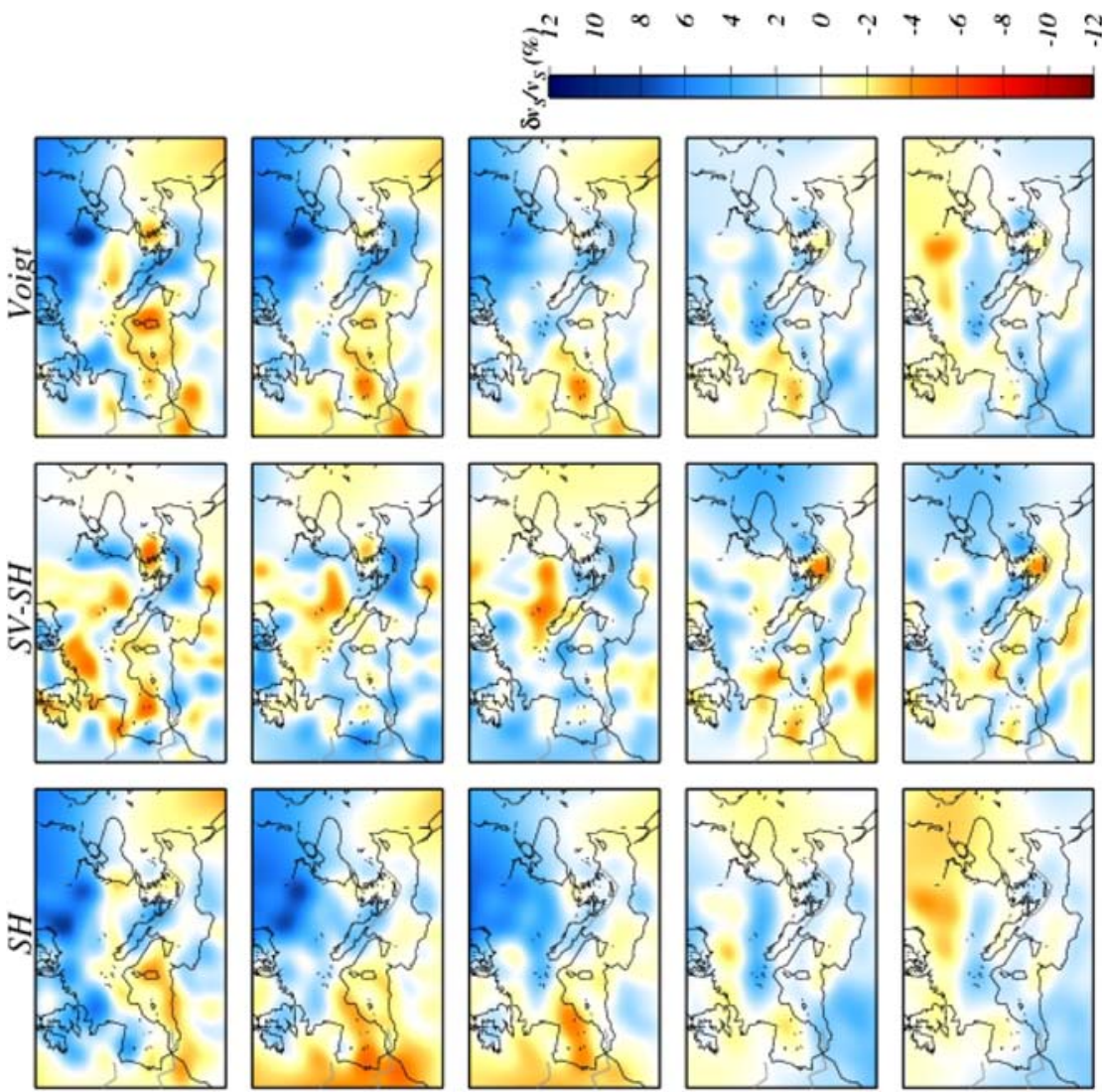

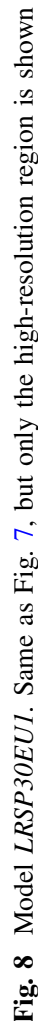
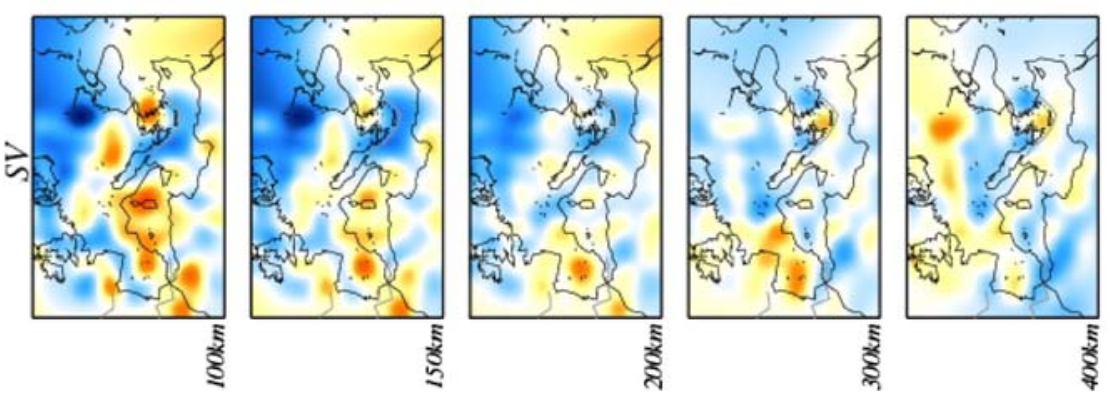

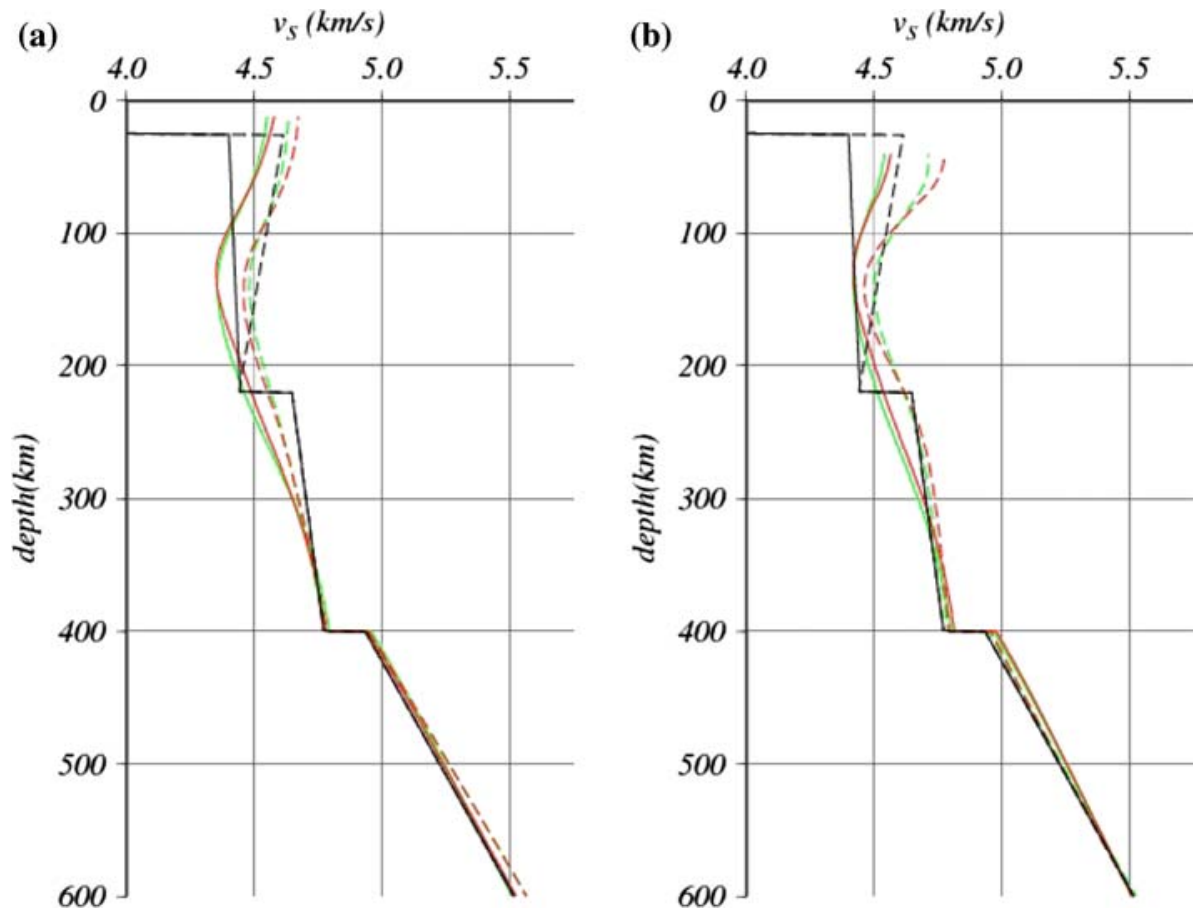

Fig. 9 Mean $v_{S V}$ (solid lines) and $v_{S H}$ (dashed) from models LRSP3OEU1 (green lines) and LRSP3OEU2 (red), computed (a) globally and (b) within the high-resolution region. Values of $v_{S V}$ and $v_{S H}$ within the variable-thickness crust are not considered; mean $v_{S V}$ and $v_{S H}$ are only shown at depths that are at least somewhere larger than the depth of the Crust2.0 Moho. $v_{S V}$ and $v_{S H}$ from PREM (black) are shown for comparison. Our spherically symmetric, isotropic starting model of the mantle (not plotted here for simplicity) is found by extending the 400-220 km trend of PREM $v_{S}$ to shallower depths, resulting in a single straight line between $400 \mathrm{~km}$ and the Moho

The global pattern of lateral variation in radial anisotropy from LRSP30EU2 (Fig. 10) is consistent with that observed by Ekström and Dziewoński (1998), Boschi and Ekström (2002) and Kustowski et al. (2008b), with the strongest anomaly at $\sim 150 \mathrm{~km}$ depth under the Pacific, and a clear ocean-continent signature at depths $<150 \mathrm{~km}$.

Under Europe and the Mediterranean Basin (Fig. 11), radial anisotropy is characterized by a complex pattern of spatial frequency higher than that of either $\delta v_{S H} / v_{S H}$ or $\delta v_{S V} / v_{S V}$. In view of the resolution analysis above (Sect. 2), it is likely that, within this region, most of the radially anisotropic signal in our images is an artifact resulting from differences in $v_{S H}$ and $v_{S V}$ resolution, particularly at depths $\geq 150 \mathrm{~km}$. At shallower depths, the patterns of $\delta v_{S H} / v_{S H}$ or $\delta v_{S V} / v_{S V}$ are qualitatively very similar: fast eastern European craton and Aegean arc, slow western Mediterranean, Aegean sea, and Balkans. High-spatial-frequency variations in anisotropy are then likely to be the fictitious effect of the different coverage of Love- versus Rayleigh-wave data. The top $\sim 100 \mathrm{~km}$ of the upper mantle underlying northern Germany, Belgium and the Netherlands are characterized by largerthan-average anisotropy, with low $v_{S V}$ and high $v_{S H}$. Given the dense station coverage in the region, and the good resolution of both $\delta v_{S H} / v_{S H}$ and $\delta v_{S V} / v_{S V}$ in this depth range, we believe this particular feature to be robust. 


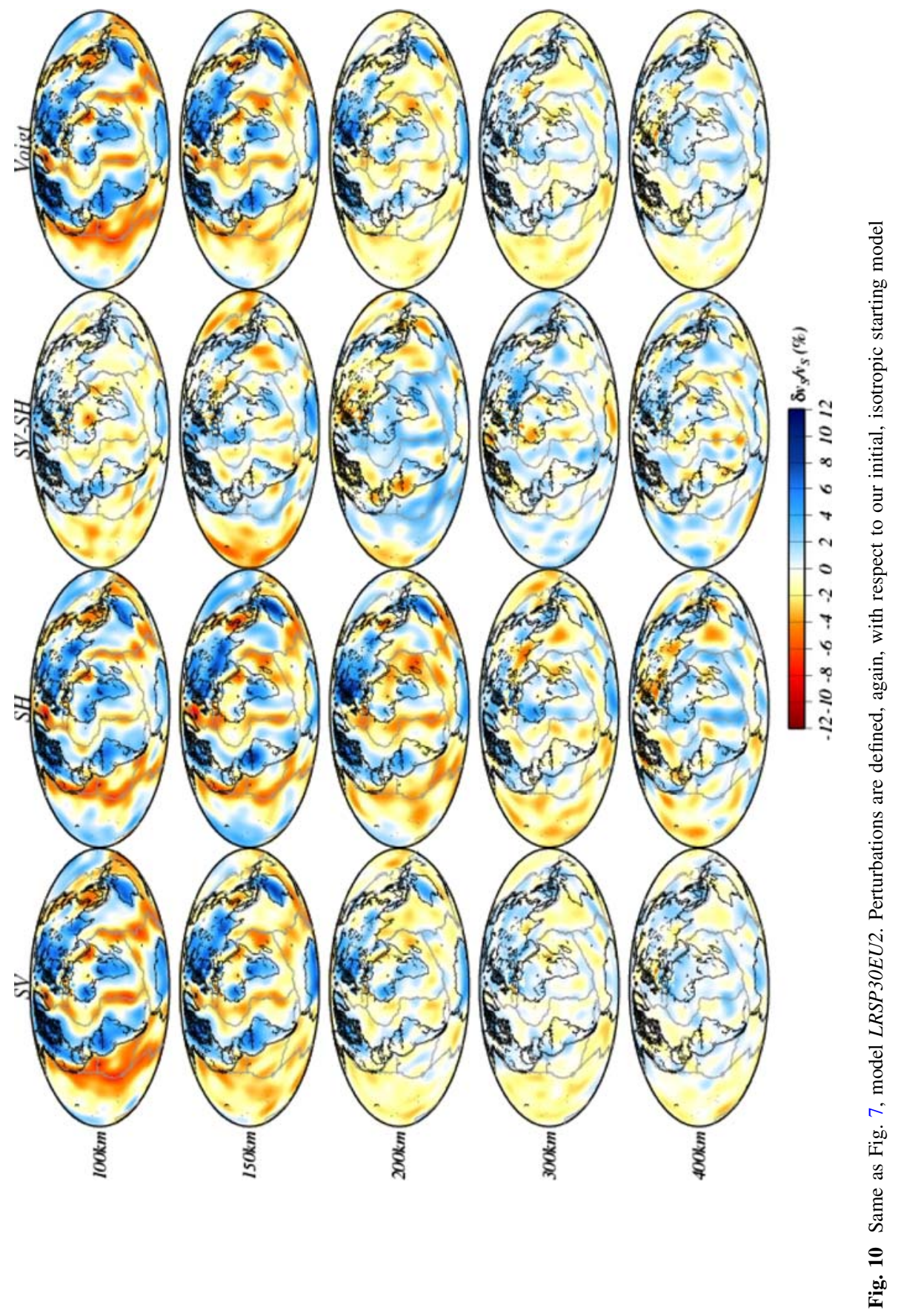



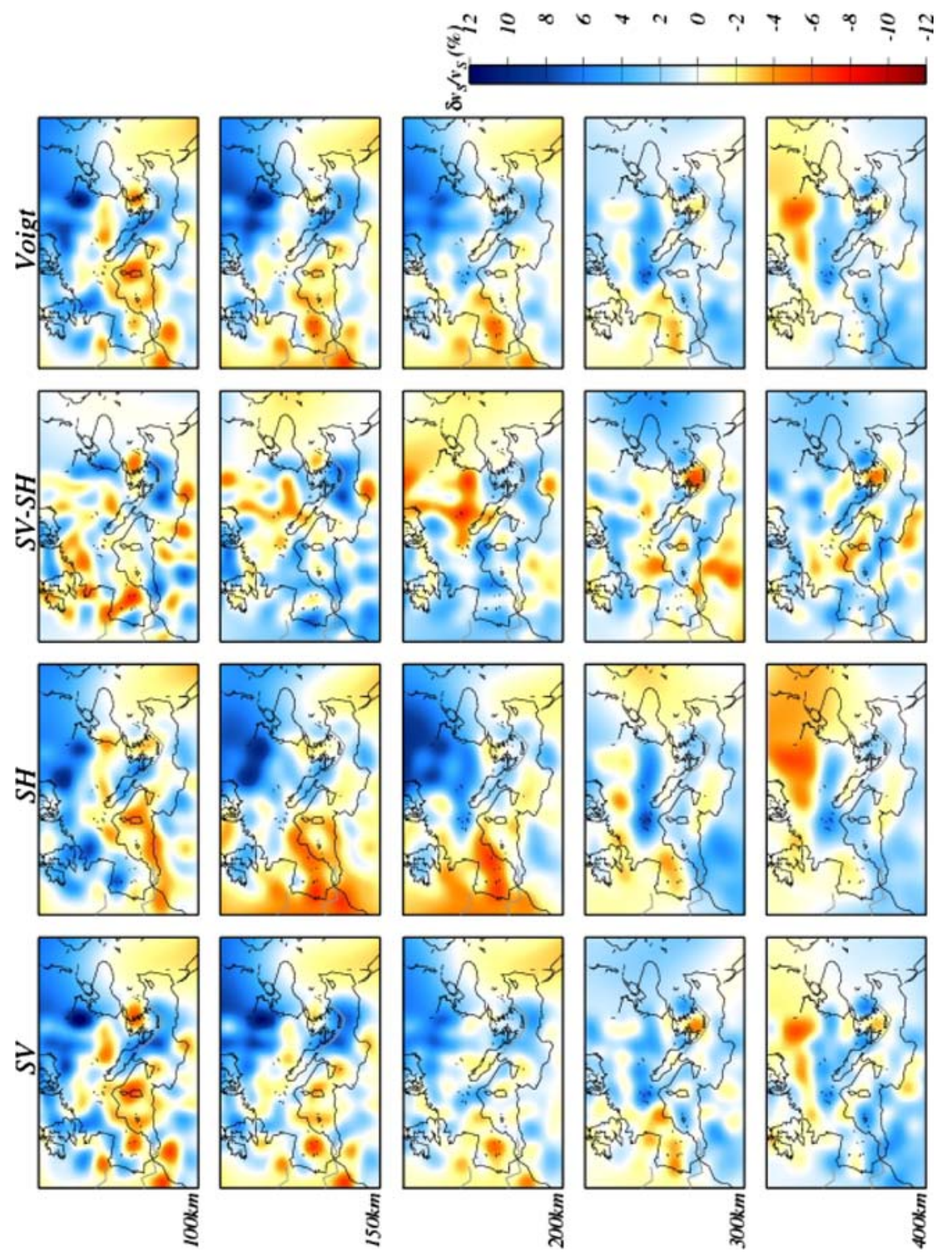

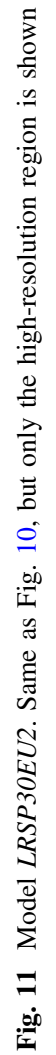


The closure of Tethys, and the associated convergence of the African and Eurasian plates, have given rise to a number of episodes of subduction, documented by tectonic reconstructions (e.g., Capitanio and Goes 2006), and confirmed, to a large extent, by LRSP3OEU2, as shown in the vertical sections of Fig. 12. Because $\delta v_{S H} / v_{S H}$ is not well constrained at depths $>100 \mathrm{~km}$, we limit the following discussion to maps of $\delta v_{S V} / v_{S V}$.

The presence of subducted material under the Iberian peninsula and the western Mediterranean is expected as a result of the African plate subducting under Iberia, in the upper to middle Tertiary, as reconstructed by Dercourt et al. (1986) (see Figs. 3, 4 in their article) and de Jonge et al. (1994). Subduction of European lithosphere under Africa is, on the other hand, associated with the Alpine orogen (Marchant and Stampfli 1997; Lippitsch et al. 2003). The top-left and top-middle panels of our Fig. 12 are in qualitative agreement with Figs. 8 and 10, respectively, in de Jonge et al. (1994). Consistent with the more recent studies of Wortel and Spakman (2000) and Capitanio and Goes (2006), we infer from Fig. 12 a depth extent of subducted slabs larger than that reconstructed by de Jonge et al. (1994), both under Alps and the Iberian peninsula. Given the resolution limits of both our studies, the high velocity anomaly that we map at depths $\geq 200 \mathrm{~km}$ under the Alps can be considered in qualitative agreement with the images of Lippitsch et al. (2003).

Active subduction under the Calabrian arc, and subducted material associated with the Apennines, map in Fig. 11 as a weak, but visible, narrow band of high velocity roughly following the western coast of Italy. Figure 12 (bottom-left panel) shows this anomaly to extend no deeper than $\sim 400 \mathrm{~km}$ into the mantle. Aegean-arc subduction, documented as a large-scale, sharp fast feature in numerous studies (de Jonge et al. 1994; Wortel and Spakman 2000; Piromallo and Morelli 2003; Schmid et al. 2008), is generally found to have continued to much larger depths, possibly into the lower mantle. While our data have little sensitivity to lower-mantle structure, the bottom panels of Fig. 12 confirm a depth extent of $\sim 700 \mathrm{~km}$ for this slab. Interestingly, they also show the slab to dip almost vertically, in contrast with tomographic maps based on body-wave data (de Jonge et al. 1994; Wortel and Spakman 2000; Piromallo and Morelli 2003; Schmid et al. 2008). This discrepancy is most likely an effect of lack of resolution, and it is not clear which model should be trusted: we have shown in Sect. 5 that our maps can be subject to vertical smearing, but Fig. 9 of Piromallo and Morelli (2003) indicates that body-wave-based maps are smeared in the same direction that their imaged slab dips to.

Possible tectonic scenarios leading to subduction under the Carpathian region are analyzed by Fan et al. (1998). Our Fig. 11 shows a low-velocity zone under most of Romania, down to $\sim 150 \mathrm{~km}$ depth. Below, and down to at least $400 \mathrm{~km}$ depth (Fig. 12), a broad fast anomaly becomes dominant. This feature is geographically connected to the broad, fast anomaly clearly associated with the eastern European craton.

\section{Phase-Velocity Maps}

At each reference $2^{\circ} \times 2^{\circ}$ pixel, we compute the radial integrals of the products of $\delta v_{S V} / v_{S V}$ and the corresponding kernels, and of the products of $\delta v_{S H} / v_{S H}$ and the corresponding kernels (Fig. 3), to determine sets of Love- and Rayleigh-wave phase velocity maps associated with our models. Phase-velocity maps whose horizontal parameterization coincides with that of our three-dimensional models are found. The contribution of starting model (Crust 2.0 plus a spherically symmetric mantle at the first iteration, LRSP3OEU1 at the second iteration) and heterogeneity model (LRSP3OEU1 and LRSP3OEU2, respectively) are calculated separately and then summed. In Figs. 13 through 20, the results of 


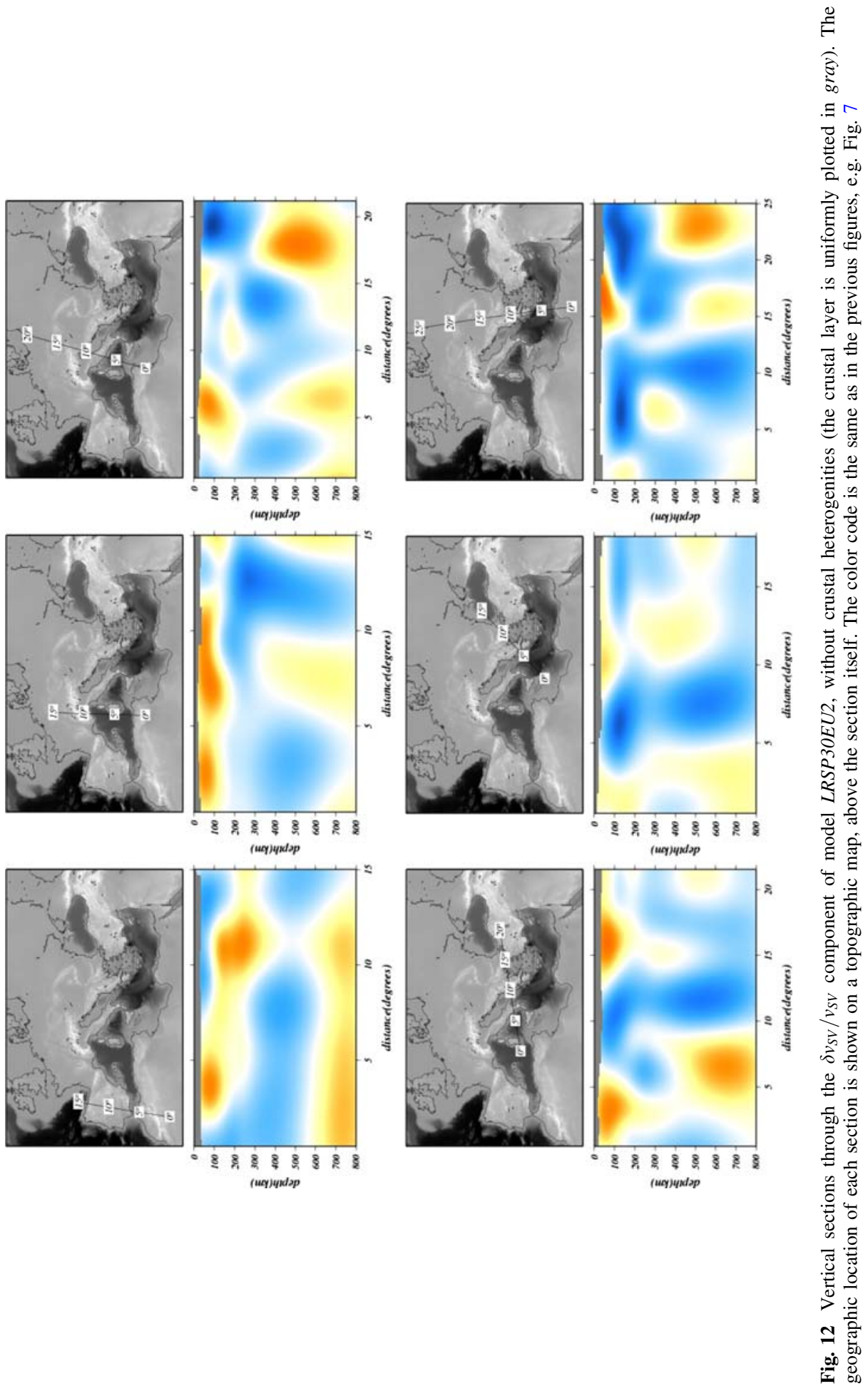



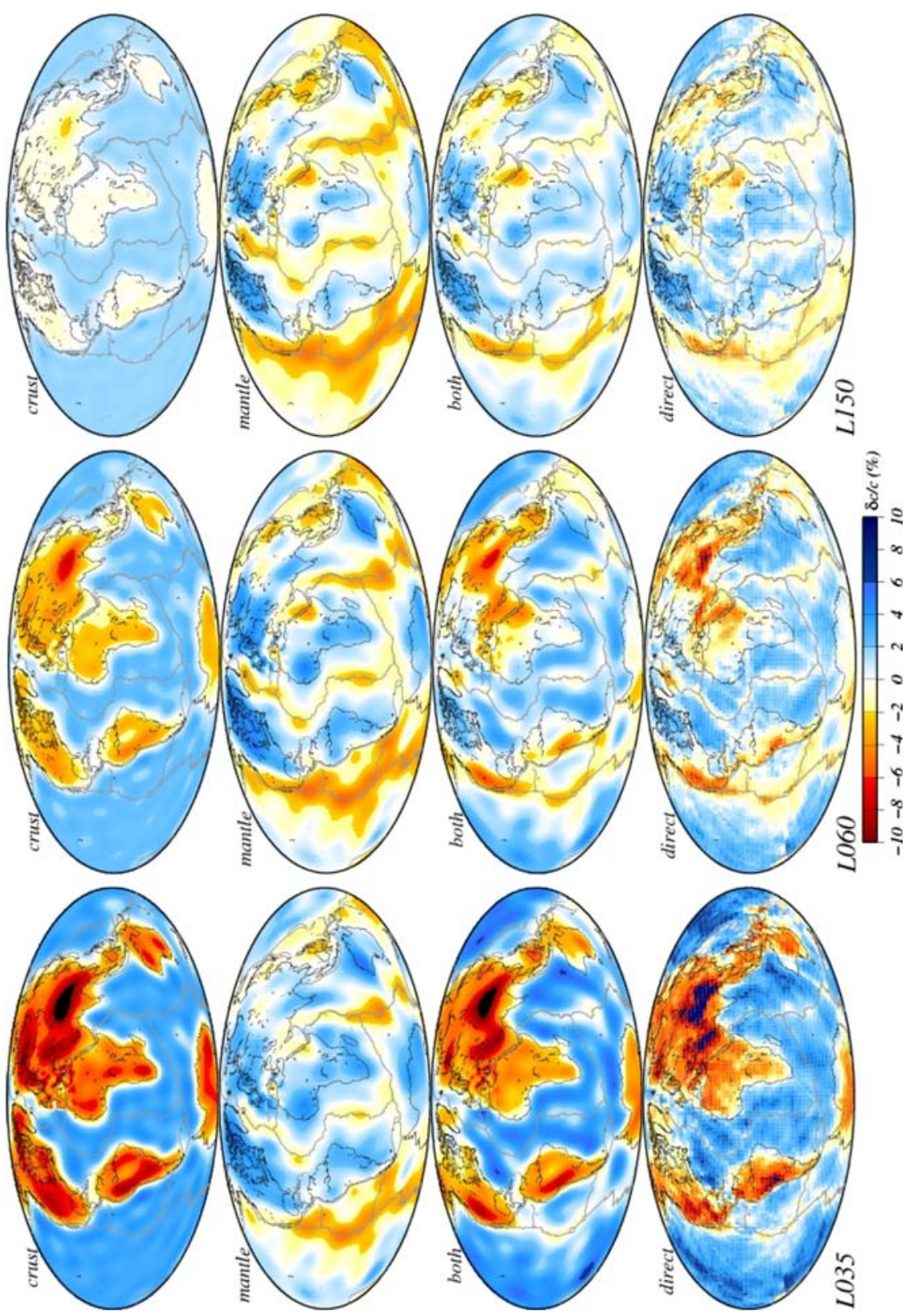

竞:

雷导

흔

.

$\frac{\pi}{2} \geq$

ํํำ

응

.

를

0

苞

垴可

हี

은

过官

हก

क D

焉 क

$\exists \stackrel{n}{=}$

ठํ.

产导

宾

$\therefore$ 뉸

뉸

잉

응 흥

훰

号吉

¿

牙过

तथे

¿

잉. ह

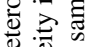

웡

릉

ป 웜

正

总茎营

$\because$ is

을 芯 
this exercise are compared with those of conducting at each period an independent inversion of our phase-anomaly database, to directly find the corresponding phase-velocity map. In the latter endeavour, we make use of a pixel parameterization analogous to that of Boschi (2006): $3^{\circ} \times 3^{\circ}$ globally, $1^{\circ} \times 1^{\circ}$ in a high-resolution region coinciding with Europe and the Mediterranean Basin. The inversion algorithm also coincides with that of Boschi (2006). At the global scale, the good match between the phase velocities derived from LRSP3OEU1 and LRSP3OEU2, and those found directly from the data, is a proof of our method's internal consistency (Boschi and Ekström 2002). Comparing Figs. 14 with 16, it can be noticed that LRSP3OEU2 matches two-dimensional phase-velocity tomography slightly better than LRSP3OEU1. This is mostly a consequence of updating sensitivity kernels, after the first iteration, based on LRSP3OEU1: notice the difference between the second-from-bottom, right panel of Fig. 14, and the top right panel of Fig. 16 (150 s Rayleigh waves). The latter is characterized by more prominent slow regions corresponding to rifting in western North America and eastern Africa, in agreement with the phase-velocity tomography (bottom panels) result. A similar effect can be seen along mid-oceanic ridges in the $60 \mathrm{~s}$ Rayleigh-wave maps.

At the scale of Europe and the Mediterranean basin, the correlation is not as high as beetween the large-scalelength components of the phase-velocity maps in Figs. 13, 14, 15 and 16, but it is still high. The decorrelation or, even, anti-correlation between the phasevelocity of $35 \mathrm{~s}$ Rayleigh waves as predicted by our crustal model (essentially Crust2.0) versus both $L R S P 30 E U 1$ and LRSP3OEU2 is surprising. It is not necessarily fictitious, but suggests that the accuracy of Crust 2.0 in this area should be re-evaluated, and/or a higherresolution crustal model identified. Indeed, it can be noticed from the left panels of Fig. 18 that the mantle-only contribution to phase velocity (second from top) is better correlated with the phase-velocity map found by direct inversion (bottom), than the phase-velocity map derived from both crust and mantle heterogeneity (second from bottom) is. On the other hand, Crust 2.0 predicts the phase velocity of Love waves more effectively: from the left panels of Fig. 17 it is clear that the contribution of mantle anomalies is, in that case, much less important, and yet the directly-inverted phase velocities are reproduced well. It also appears that having Crust 2.0 as the starting model helps to reproduce the low velocities associated with the Adriatic plate, possibly smeared in the direct phase-velocity inversion of $35 \mathrm{~s}$ Love waves.

Many patterns corresponding to upper-mantle velocity anomalies are seen in the LRSP3OEU1-based phase-velocity maps shown in Figs. 17 and 18, in agreement with the corresponding maps obtained by inverting the data directly. See in particular the fast eastern European craton (150 s Love waves, $60 \mathrm{~s}$ and $150 \mathrm{~s}$ Rayleigh waves); fast Aegean arc (150 s Love waves, all Rayleigh-wave periods); slow Aegean sea and western Anatolia (at all Love- and Rayleigh-wave periods, at least to some extent); a fast anomaly under the Alps (150 s Love and Rayleigh waves). The high correlation found by Fry et al. (2008) between intermediate-period Rayleigh waves and heat-flow based estimates of uppermantle temperatures suggests that many of these features can be explained in terms of lithospheric thickness (Sect. 10). High 35s Love-wave velocities under the Atlantic, where the crust is very thin and surface waves therefore propagate through the faster uppermost upper-mantle, are also reproduced well by our model.

The above considerations hold for the maps predicted on the basis of model LRSP3OEU2 (Figs. 19, 20), which are however generally characterized by heterogeneities of larger amplitude, in agreement with the properties of LRSP3OEU2 itself. 


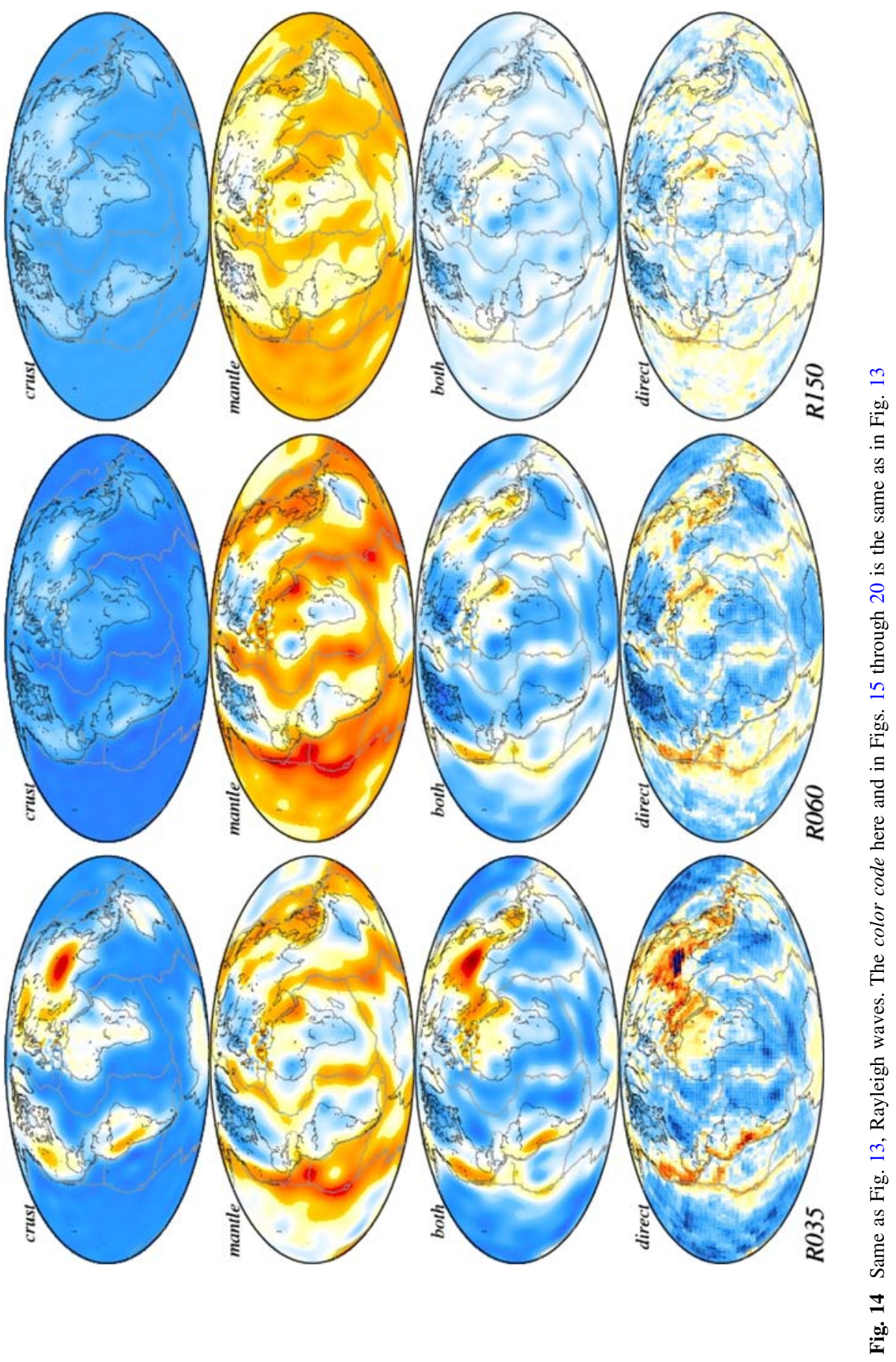




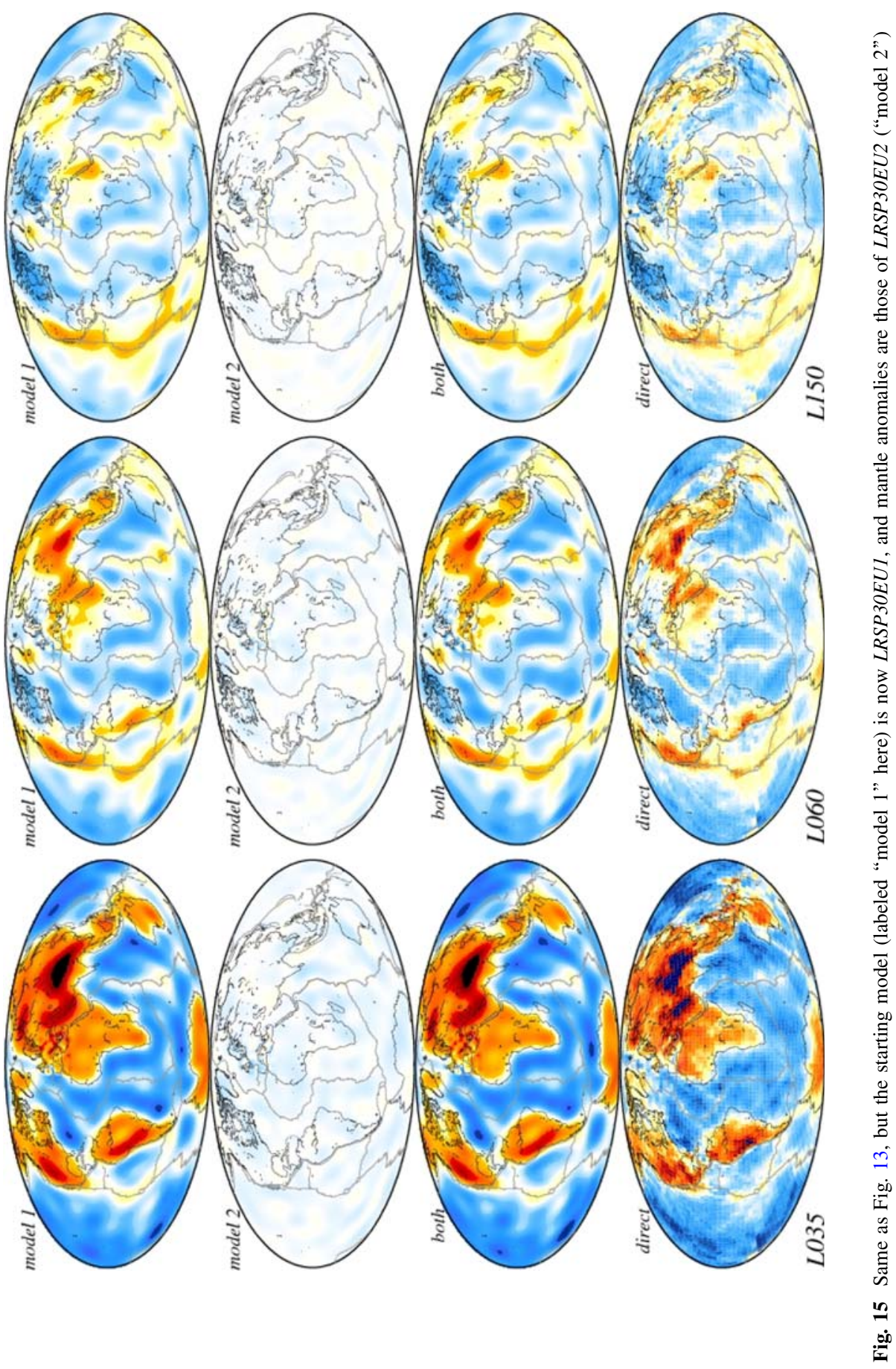




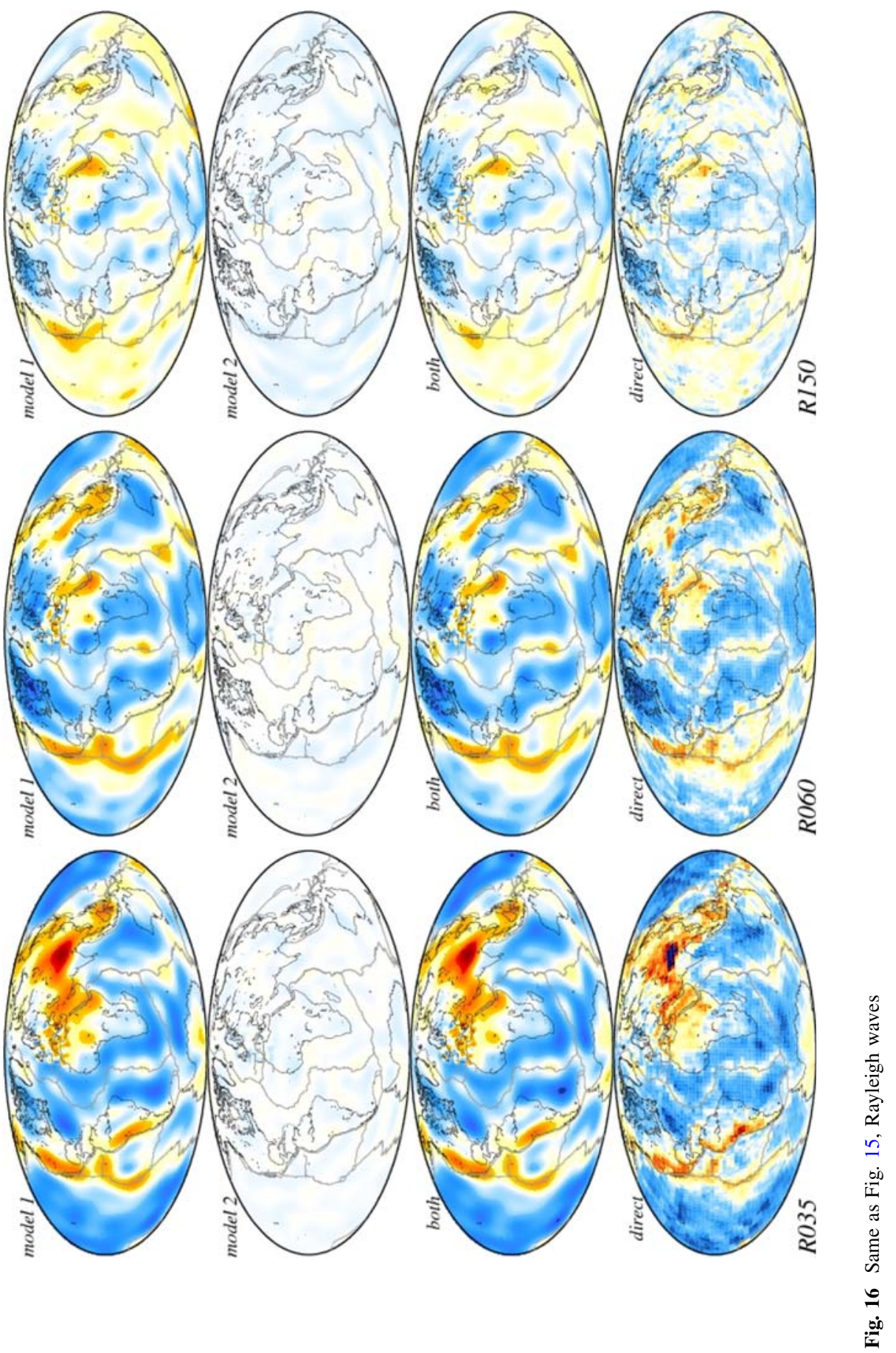



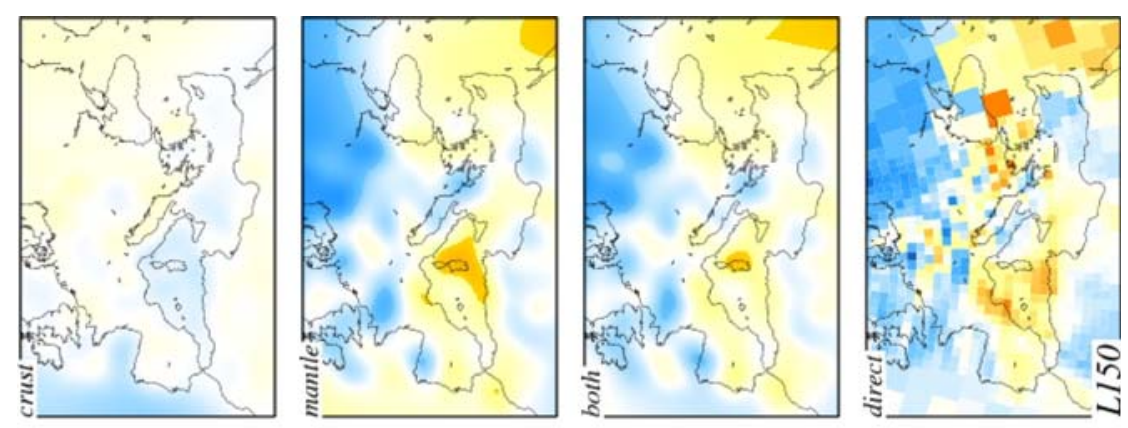

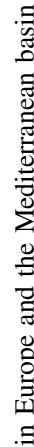
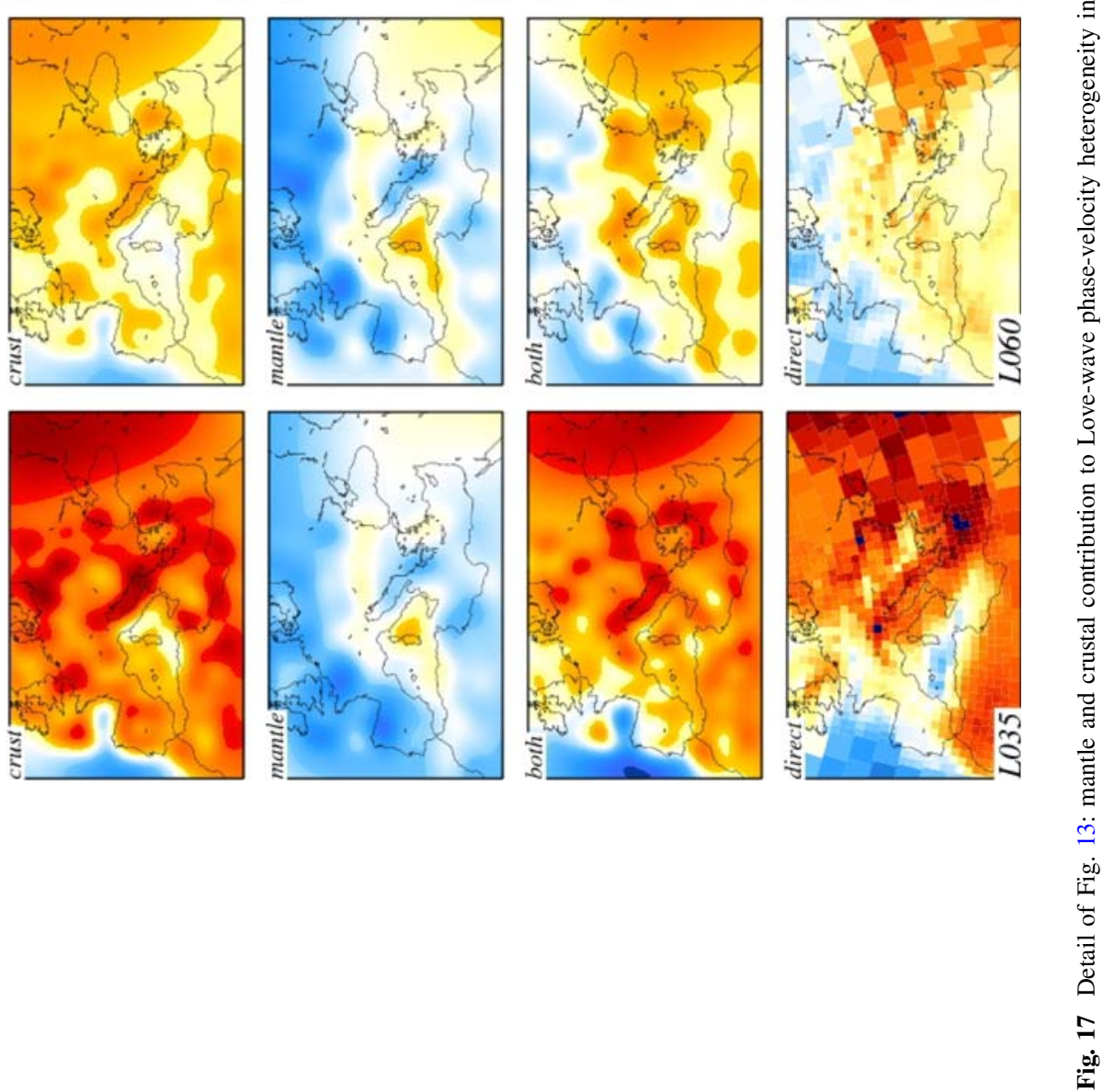

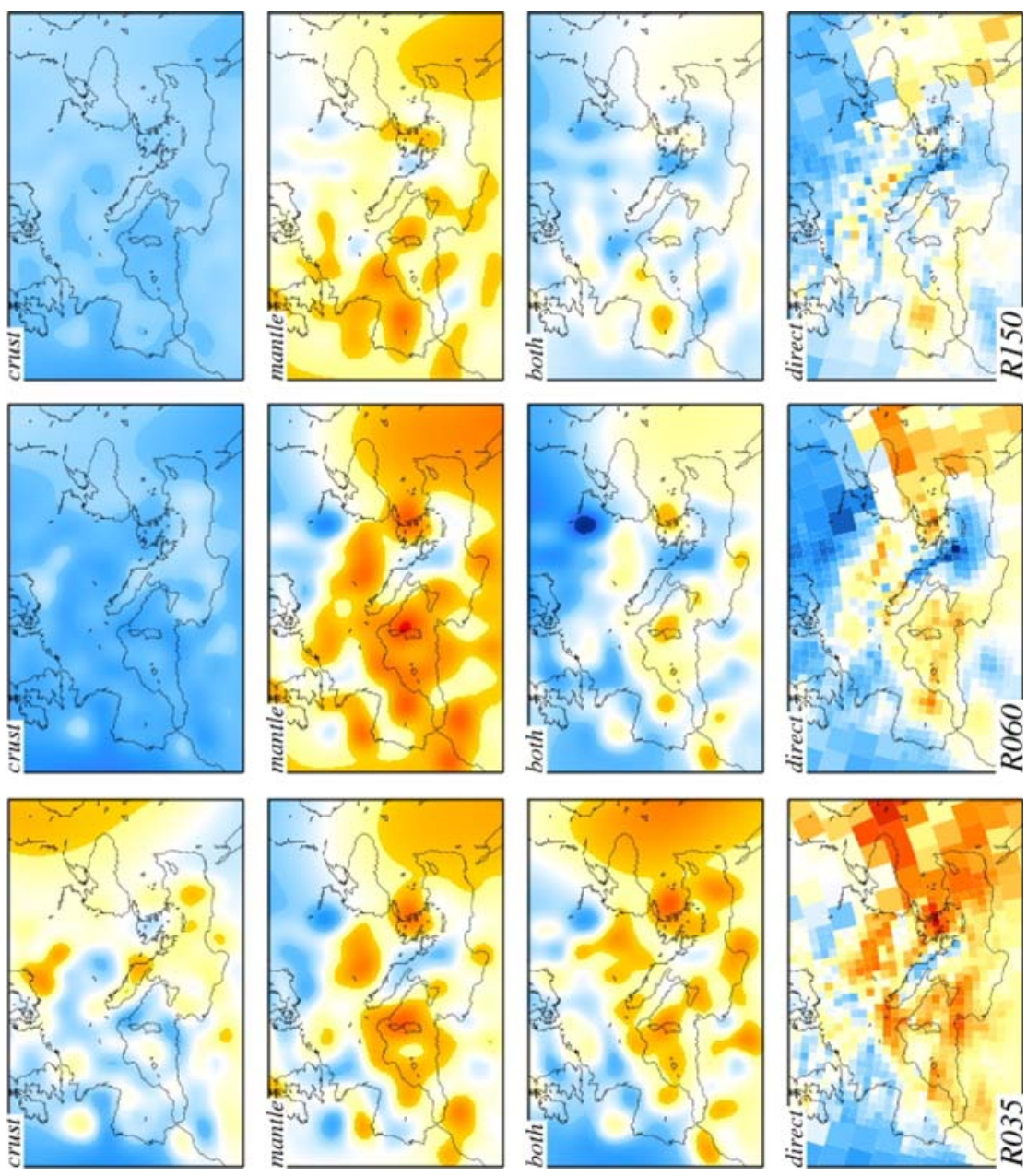

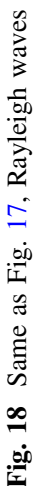



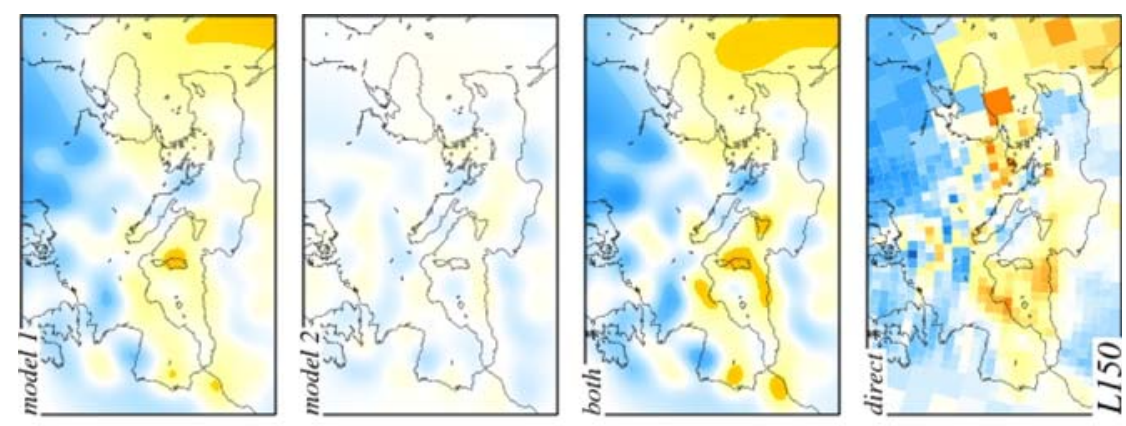

$\frac{n}{2}$
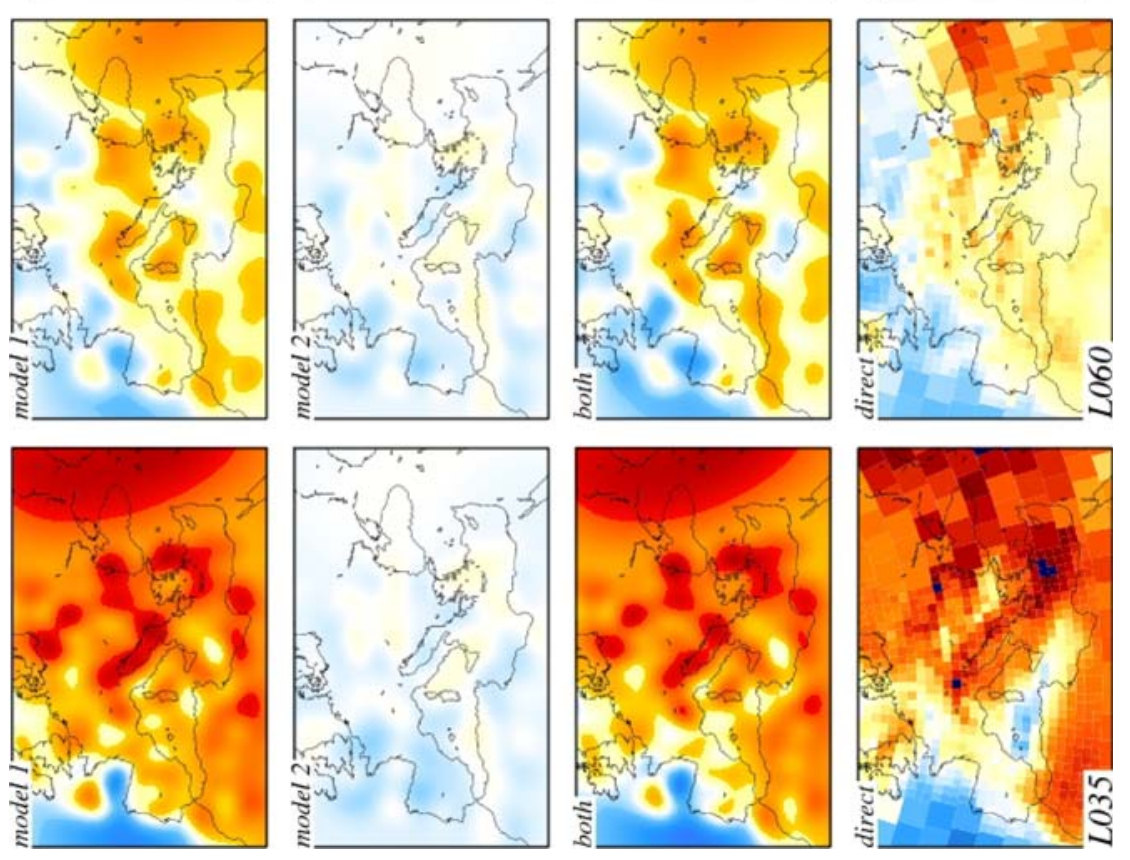

范

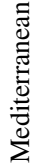

$\stackrel{2}{\Xi}$

클

ํㅡㄹ

.

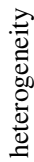

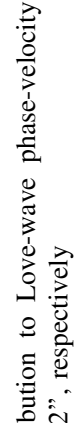

를

¿̊ำ

$\mathrm{N}^{0}$

旅:

串

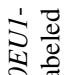

กิ

ปั

光过

$\therefore \frac{\infty}{2}$

4

స

矛》

จิ กิ

인 

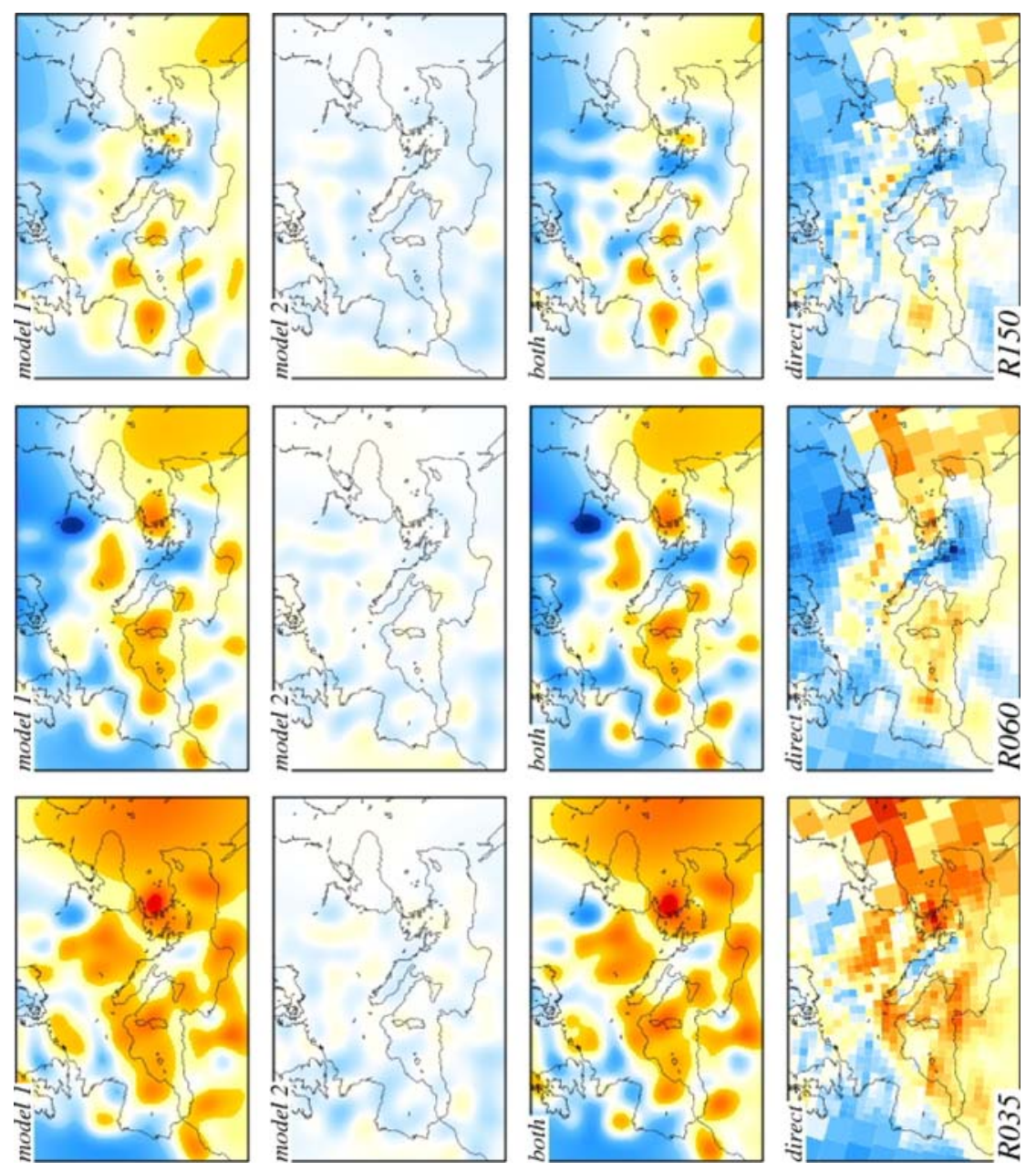

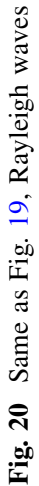




\section{Fit to the Data at Different Frequencies}

To better quantify the extent to which our three-dimensional upper-mantle models explain surface-wave phase-anomaly observations, we formally calculate the misfit between the dispersion data we inverted, and the corresponding predictions derived from the phasevelocity maps that we computed from LRSP3OEU1 and LRSP3OEU2 themselves. Based on Eq. 5, we define misfit as

$$
\frac{\sum_{m=1}^{M}\left[\sum_{i=1}^{I}\left(G_{m i} x_{i}-\delta \Phi_{m}\right)\right]^{2}}{\sum_{m=1}^{M} \delta \Phi_{m}^{2}} .
$$

where $x_{i}(i=1,2, \ldots, I)$ denote the $I=538$ (Sect. 4) coefficients of the phase-velocity model corresponding to LRSP3OEU1 or LRSP3OEU2.

We implement the expression (14) for all Rayleigh- and Love-wave periods in our database, for the phase-velocity maps derived from models LRSP3OEU1 and LRSP3OEU2, and for those found by direct inversion of the phase-anomaly data at each period. The results are shown in Fig. 21. The fit of Rayleigh-wave data achieved by LRSP3OEU1 is very low, largely as a result of the starting model not predicting those data at all (we have verified that the mantle-only contribution to misfit is positive, as anticipated by the discussion in Sect. 8); one iteration of our procedure, improving mantle structure and the associated sensitivity functions, brings the misfit achieved by LRSP3OEU2 very close to that of the direct phase-velocity inversions. On the contrary, the fit to Love-wave data achieved by LRSP3OEU1 is already as high as that of LRSP3OEU2.

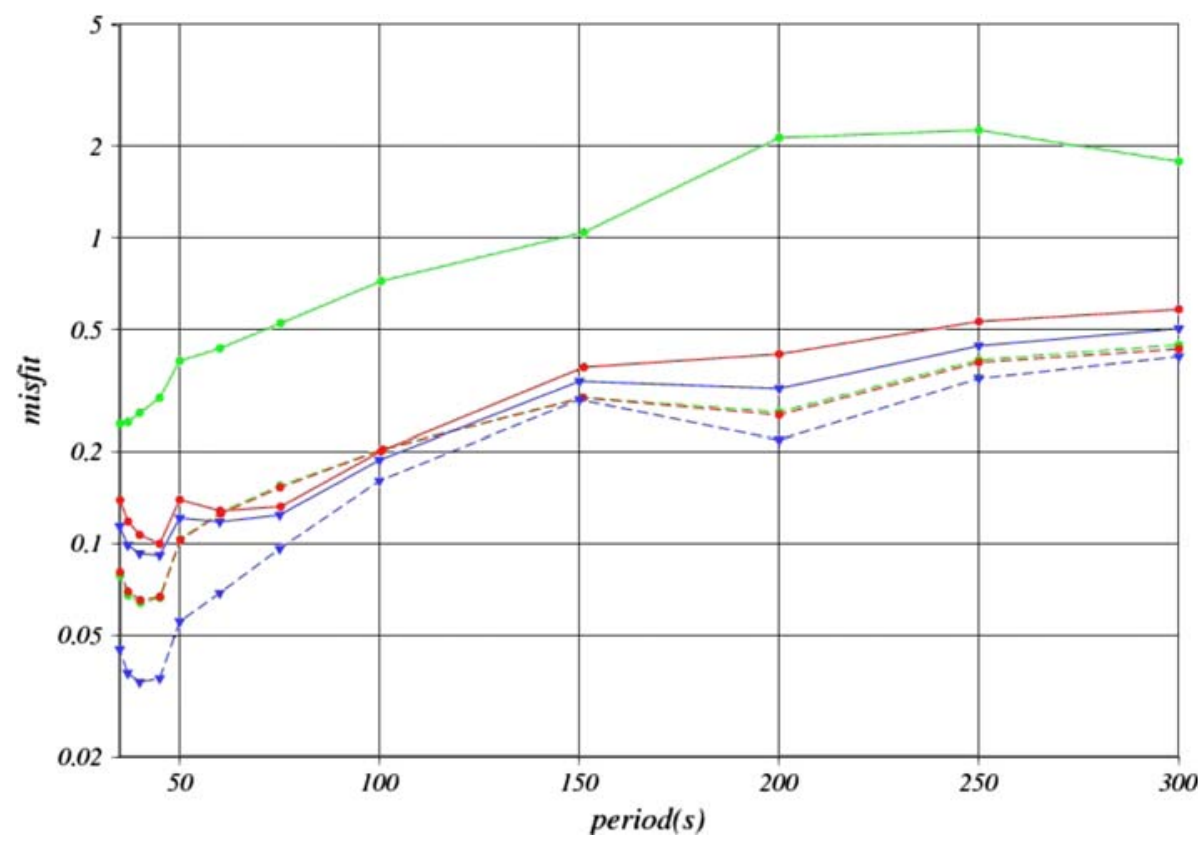

Fig. 21 Misfit, as defined by Eq. 14, to Rayleigh- (solid lines) and Love-wave (dashed lines) phase anomalies at different periods, achieved by our models (circles) LRSP3OEU1 (green lines) and LRSP3OEU2 (red). The misfit achieved by phase-velocity maps found by direct inversion of the data at each surface-wave mode is shown for comparison (triangles, blue lines). Notice that the scale on the vertical axis is logarithmic 
It is not surprising that misfit grows with increasing period: intermediate-period (between 50 and $150 \mathrm{~s}$ ) surface waves are sensitive to deep structure, harder to resolve; waves at periods $\geq 200 \mathrm{~s}$ are more difficult to measure, and, as noted in Sect. 2, observations at those periods are consequently much less numerous. Rather, the fact that a misfit $<0.5$ is achieved by LRSP3OEU2 at all periods $\leq 200 \mathrm{~s}$ (for both Love and Rayleigh waves) indicates that the data-weighting scheme described in Sect. 2 is appropriate.

\section{Comparison with Independent Models}

\subsection{Global Tomography}

Accurately mapping global structure is essential to avoid trade-offs between the low- and high-resolution portions of our models, with the subsequent loss of resolution. We have verified that our models are well correlated with the pattern of high and low shear velocities observed in the upper mantle from independent databases. As an example, we show in Fig. 22 how LRSP30EU2 compares at $100 \mathrm{~km}$ depth with model SMEAN of Becker and Boschi (2002) and with the more recent model of Simmons et al. (2006) (TX2007 hereafter). Because both SMEAN and TX2007 are isotropic models, derived at least partly from body-wave data that are sensitive to both $v_{S H}$ and $v_{S V}$, we compare them to the Voigt average

$$
\frac{\delta v_{S}}{v_{S}}=\frac{2}{3} \frac{\delta v_{S V}}{v_{S V}}+\frac{1}{3} \frac{\delta v_{S H}}{v_{S H}}
$$

(Babuska and Cara 1991) of our $v_{S H}$ and $v_{S V}$ maps, rather than with the better constrained $v_{S V}$.

The distribution of slow and fast heterogeneity in the maps of Fig. 22 has been often explained in the framework of plate tectonics (Ekström and Dziewoński 1998) and does not need to be discussed again. In agreement with Becker and Boschi (2002), the models are very similar. This is remarkable if one considers that TX2007 was derived from bodywave data only, and LRSP3OEU2 only from surface-wave observations. SMEAN, like most other global tomographic models of $v_{S}$, was obtained from a combination of body-wave and surface-wave data, including surface-wave overtones (Ritsema et al. 2004). Some differences in the shape of anomalies (see, e.g., the "blobby" mid-Atlantic and Indianocean ridges, and Red sea rifting area) can be ascribed to the coarser (362 free parameters) global horizontal resolution of LRSP30EU2, equivalent to harmonic degree $\sim 18$, while SMEAN is defined up to harmonic degree 30, and TX2007 is described horizontally by $16,2002^{\circ} \times 2^{\circ}$ pixels.

The pattern of velocity anomalies is easier to constrain than their amplitude. Of the models of Fig. 22, LRSP3OEU2 has the highest amplitude, and SMEAN the weakest, while TX2007 is somewhere in between.

\subsection{European Tomography}

Even in the presence of large regional databases, structure of smaller scalelength is difficult to image, and, as we zoom in on Europe and the Mediterranean basin (Fig. 23), this is reflected by a loss of correlation between independent tomographic models. A careful analysis of Fig. 23 shows, however, that many features are shared by all models: a sharp transition from low to high velocities corresponding to the western margin of the eastern European craton, down to $\sim 250 \mathrm{~km}$ depth; high velocity, at most depths, corresponding to 

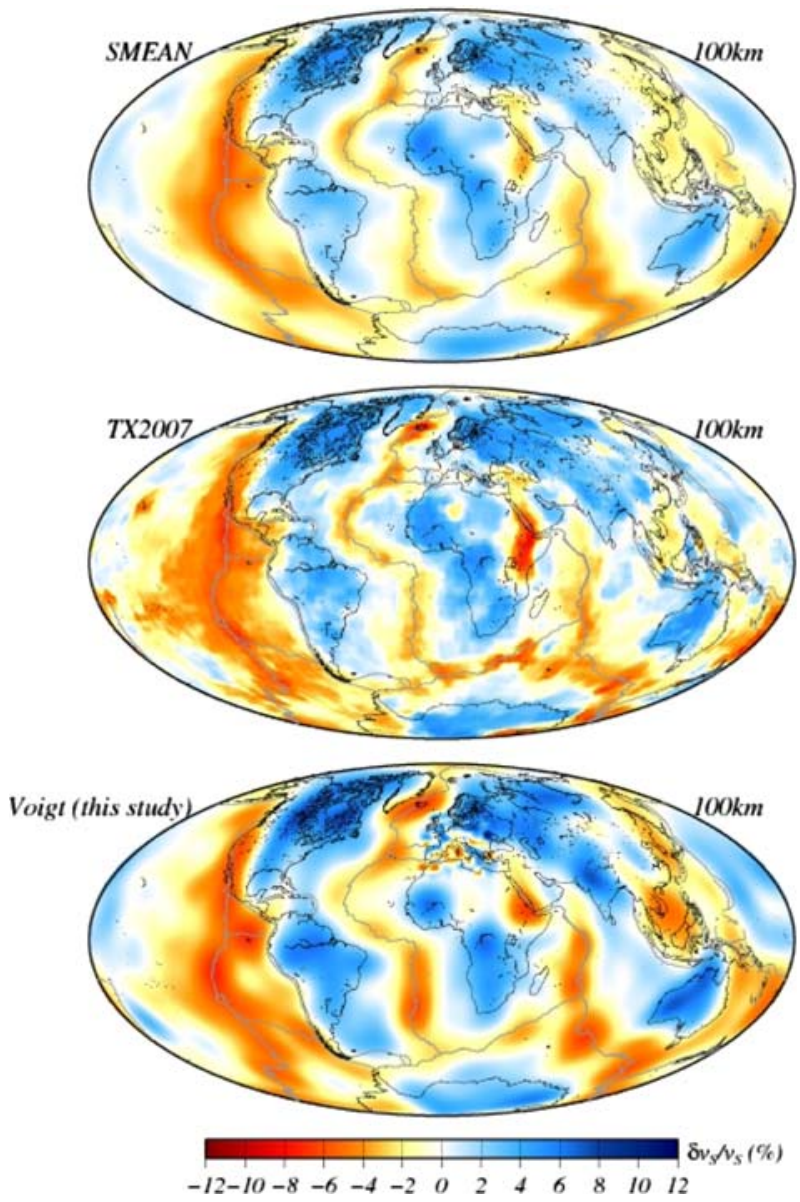

Fig. 22 Tomography $\delta v_{S} / v_{S}$ models of Becker and Boschi (2002) (top) and Simmons et al. (2006) (middle), compared with LRSP3OEU2 (bottom) at $100 \mathrm{~km}$ depth

the Aegean arc and the associated subduction; high velocities, again, along the Italian peninsula and the Calabrian arc; low velocities under Sardinia, Corsica and the western Mediterranean down to $\sim 200 \mathrm{~km}$ depth; low velocities under the Carpathians, central Europe and Germany, down, again, to $\sim 200 \mathrm{~km}$ depth.

The models nevertheless differ in many respects. The P-wave velocity model of Piromallo and Morelli (2003) is characterized, at 100-150 km depth, by a strong fast anomaly along the Dinarides. This feature is reproduced only partially by Schmid et al. (2008), and absent from all the other models discussed here. It remains unclear whether a similar feature is present in the images discussed by Bijwaard et al. (1998) and Wortel and Spakman (2000).

The model of Boschi et al. (2004) is generally slow under the Alps, where we, as well as Peter et al. (2008), find a relatively strong fast anomaly at depths $>250 \mathrm{~km}$. A similar feature, albeit somewhat displaced and extending to a wider depth range, is visible in the models of both Piromallo and Morelli (2003) and Schmid et al. (2008). Since LRSP3OEU2 and the model of Boschi et al. (2004) were otherwise derived via exactly the same 

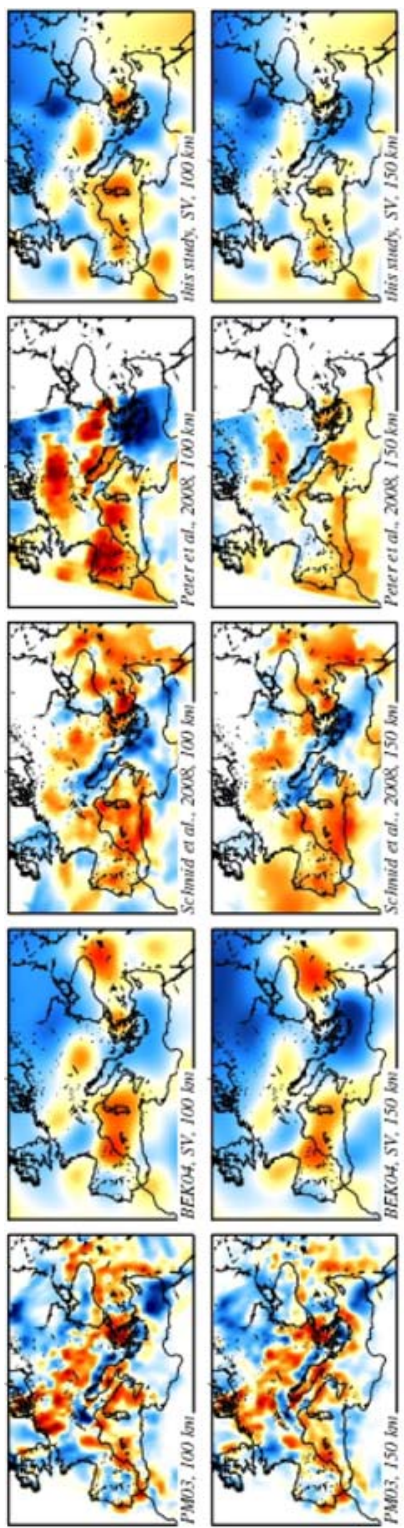
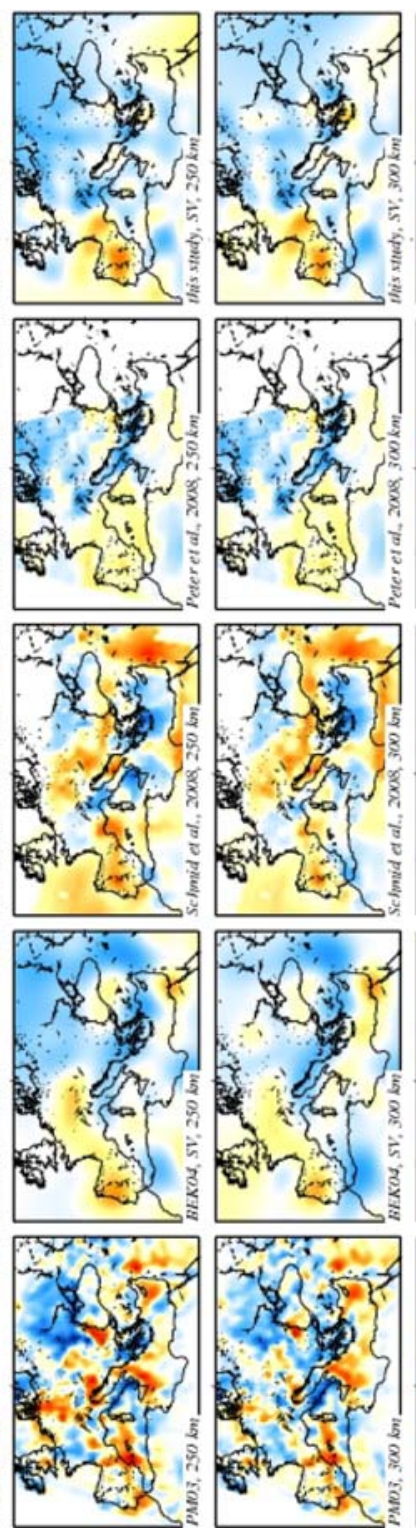
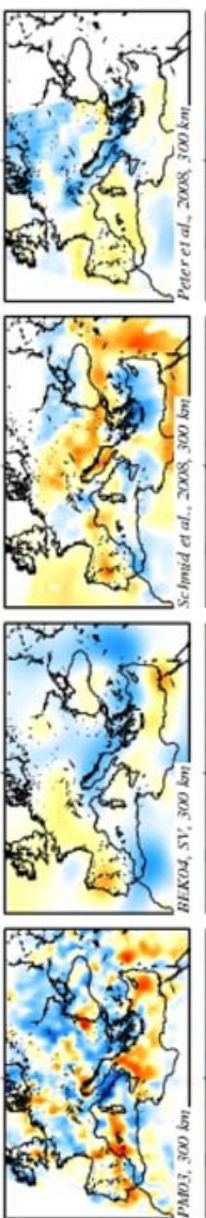

ธิ

.

$\stackrel{2}{\circ}$

青等

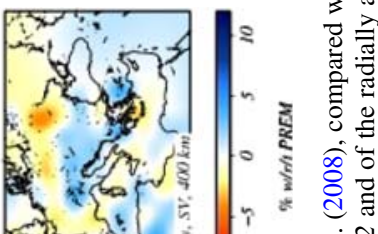

जिए?

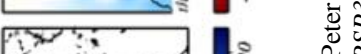

$\rightarrow$ की

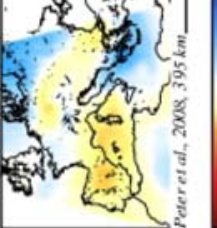

एक्रण: की के

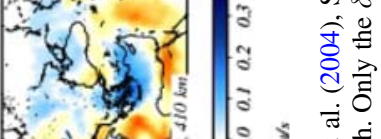

i.

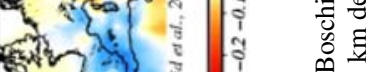

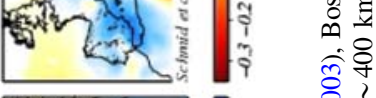

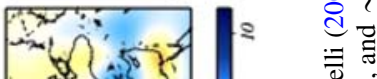

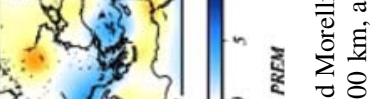

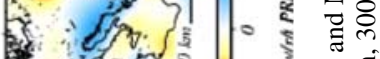

क्षे है

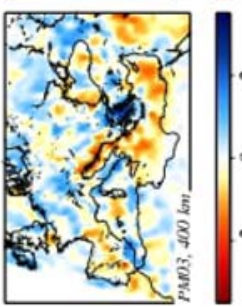

ำ

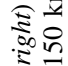

2 ह

훙 递要

능

ब

ㅇ.

종

춘 웡

宛范

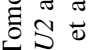

$\rightarrow$ 뇍:

$\pi$ \%

ํํㄴ 
algorithm, it is likely that this discrepancy be caused by the refined data coverage and parameterization of LRSP3OEU2, which should then be considered more reliable.

LRSP3OEU2 and the model of Boschi et al. (2004) also differ under the western Mediterranean down to $150 \mathrm{~km}$ depth, where the latter's uniformly slow character is replaced by a more heterogeneous map, with slow maxima under Sardinia, Corsica and the eastern coast of Spain. Complicated patterns of heterogeneity are also found, in this area, by Piromallo and Morelli (2003), Schmid et al. (2008) and Peter et al. (2008).

The $v_{S V}$ model of Peter et al. (2008), derived from the same Rayleigh-wave data as ours, nevertheless differs significantly from LRSP3OEU2. To a closer look, it appears that the total amount of slow and fast anomalies approximately coincides, at each geographic location, with that of LRSP3OEU2; but their vertical distribution is quite different. Peter et al. (2008) first derived a set of Rayleigh-wave phase-velocity maps (hence, many sets of Rayleigh-wave dispersion curves) by direct inversion, similar to those of Figs. 17, 18, 19 and 20 (bottom panels). In a second step they found, for each pixel of those maps, a vertical profile of $v_{S V}$ that explained the corresponding dispersion curve. This second inversion was conducted by means of a non-linear, "Monte-Carlo"-type algorithm, that could hardly discriminate between a wide range of possible solutions. The linear approach that we followed here, deriving $\delta v_{S H} / v_{S H}$ and $\delta v_{S V} / v_{S V}$ directly from phase-delay data, through a single least-squares inversion, seems to provide a more stable solution, not exceedingly sensitive to, e.g., regularization.

On the other hand, the model of Peter et al. (2008) is based on a finite-frequency approach, theoretically more accurate than the ray-theoretical one applied here. Differences in the structure mapped by the two models under the Italian peninsula (250-300 km depth) can be associated to the differences in finite-frequency and ray-theoretical maps of 150s Rayleigh-wave velocities noted by Fry et al. (2008) and Peter et al. (2008) themselves.

\subsection{Lithospheric Thickness}

The existence of significant correlation between estimates of seismic velocity, lithospheric thickness and lithospheric strength or $T_{e}$ ("effective elastic thickness") under Europe was first pointed out by Pérez-Gussinyé and Watts (2005), who compared the $v_{S}$ model of Boschi et al. (2004) with a map of thermal thickness of the lithosphere from Artemieva and Mooney (2001), and with their own maps of $T_{e}$. After updating the seismic database of Boschi et al. (2004) as described in Sect. 2 above, Fry et al. (2008) also found a high correlation between the corresponding Rayleigh-wave phase-velocity maps at intermediate periods $(\sim 60 \mathrm{~s})$, and a map of thermal thickness, defined as the depth to the $1300^{\circ} \mathrm{C}$ isotherm, from model TC1 of Artemieva (2006). The latter map is shown in Fig. 24, together with the Bouguer-coherence-based map of $T_{e}$ from Pérez-Gussinyé and Watts (2005), and (following Pérez-Gussinyé and Watts 2005) the Voigt average of our model LRSP3OEU2 at $100 \mathrm{~km}$ depth. Over the area where estimates of both $T_{e}$ and thermal thickness are available, the three observables are all correlated with one another. The eastern European craton is a distinct feature of all three maps, corresponding to strong (high $T_{e}$ ) and thick lithosphere, and high $v_{S}$. Correlation between $v_{S}$ and thermal thickness is highest in central and Southern Europe, with the strongest low- $v_{S}$ anomalies clearly associated with areas of thin lithosphere under western Anatolia, the Carpathians, Corsica and Sardinia, and an important high- $v_{S}$ anomaly corresponding to thick thermal lithosphere along the southern coast of the Balkans. These features only partially match the pattern of low and high $T_{e}$, partly as a result of the short scalelength of the features themselves (Kirby 

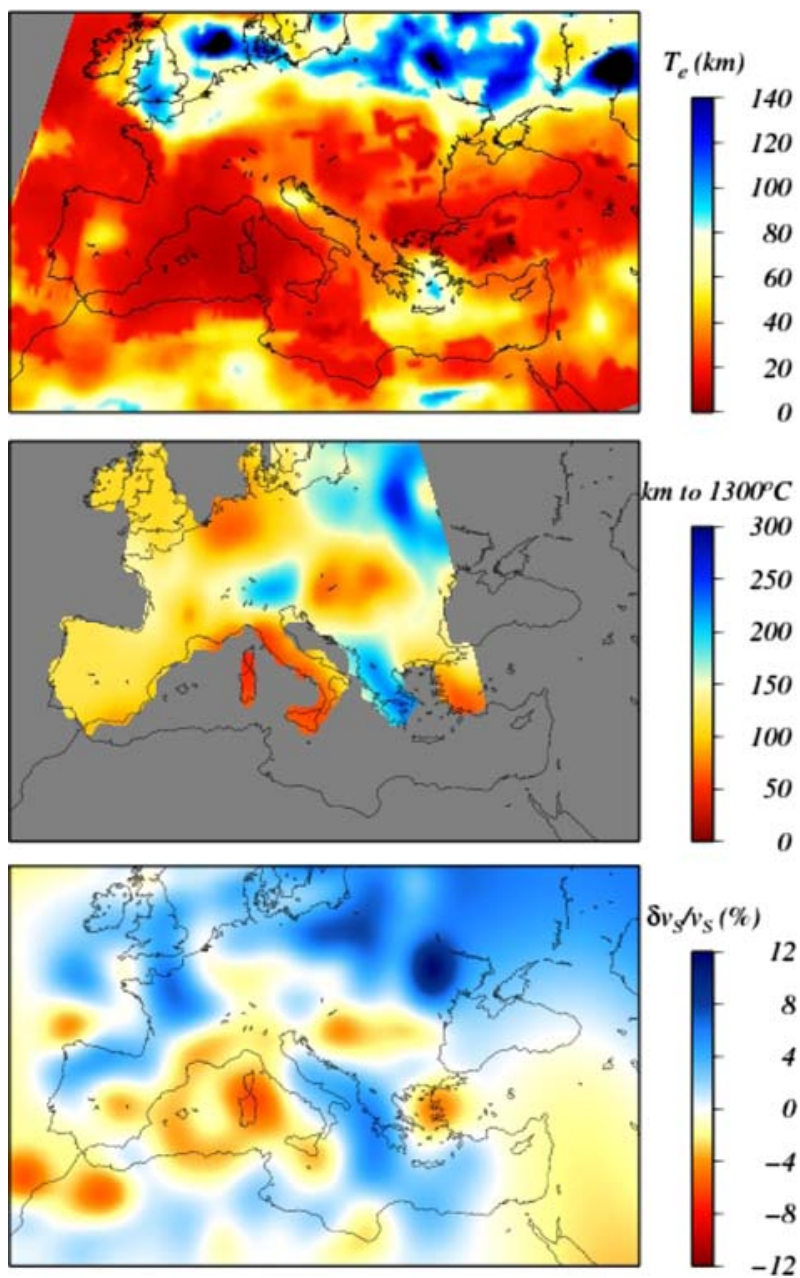

Fig. 24 Lithospheric strength, or $T_{e}$ (top), from Fig. 1a of Pérez-Gussinyé and Watts (2005); (middle) thermal thickness of the lithosphere from model TC1 of Artemieva (2006); (bottom) Voigt average $\delta v_{S} / v_{S}$ from LRSP30EU2

et al. 2008; Pérez-Gussinyé et al. 2009). In northern Europe, correlation between $v_{S}$ and $T_{e}$ is higher than that between $v_{S}$ and thermal thickness; see, in particular, the high $v_{S}$ anomaly extending from the eastern European craton to England and northern France, a region of consistently higher $T_{e}$, but low thermal thickness. Interestingly, this is also the area where we find the highest and most robust anomaly in radial anisotropy within Europe (Sect. 7 and Fig. 10).

\section{Summary}

We have taken advantage of a newly compiled database of fundamental-mode surfacewave phase anomalies, based on recordings made by seismic networks in Europe and 
around the Mediterranean basin, to identify a new model of upper-mantle, horizontally and vertically polarized shear velocity in the region.

This study is, to a large extent, an update of that of Boschi et al. (2004), with a much denser data coverage (Sect. 2) and appropriately finer parameterization (Sect. 4). We have shown in Sect. 10 and Fig. 23 how finer structure is accordingly resolved. Important improvements with respect to the model of Boschi et al. (2004) include the identification of a fast anomaly to the south-west of Italy that could be associated with the Calabrian arc, and of another fast anomaly at relatively large depth under the Alps, possibly corresponding to past subduction in the region (Sect. 7). The western Mediterranean upper mantle is characterized, at shallower depths, by a more complex low-velocity distribution than that mapped by Boschi et al. (2004), and in better agreement with other studies.

With respect to Boschi et al. (2004), we also provide a more intuitive illustration of resolution (Sect. 5), we quantify the (small) improvement in our model after one iteration of the inversion procedure, we derive (following Boschi and Ekström 2002) phase-velocity maps based on the crustal and upper-mantle heterogeneity in our models, and analyze those two contributions separately (Sect. 8).

The latter exercise shows that Crust 2.0 matches our Love-wave dispersion observations, but does not contribute to explaining the Rayleigh-wave ones, even at the shortest periods considered here. Under the assumption that the measurement technique of Ekström et al. (1997), applied here, is accurate, this suggests that in the future we should partly replace our global Crust-2.0-based reference model with a higher-resolution, regional one, derived either from the compilation of local studies (Tesauro et al. 2008), or from the inversion of ambient-noise data (Stehly et al. 2009).

Planned collaborative work leading to a consensus model of the European and Mediterranean upper mantle involves, most importantly, the compilation and tomographic inversion of a richer database, including surface-wave overteone (Lebedev and van der Hilst 2008), body-wave (Amaru et al. 2008) and ambient-noise observations (Stehly et al. 2009). In this endeavour, finite-frequency effects in wave propagation, neglected here, will ultimately have to be taken into account (Dahlen et al. 2000; Zhou et al. 2006; Fry et al. 2008; Peter et al. 2008). With this study we have proven the effectiveness of fundamentalmode surface-wave data, and of our multiple-resolution algorithm, at resolving the intermediate-scalelength distribution of regional upper-mantle heterogeneity.

Acknowledgments This article was written after an invitation by Yu Jeff Gu, to whom we are grateful. We thank Stefan Heimers for porting our Unix code to Linux, and Marta Pérez-Gussinyé for many clarifying discussions on the strength and thickness of the European lithosphere. We thank the authors of all tomographic and geophysical models that we show and discuss. All figures except for Fig. 3 were generated with the Generic Mapping Tools software (Wessel and Smith 1991).

\section{References}

Amaru ML, Spakman W, Villaseñor A, Sandoval S, Kissling E (2008) A new absolute arrival time data set for Europe. Geophys J Int 173:465-472. doi:10.1111/j.1365-246X.2008.03704.x

Artemieva IM (2006) Global $1^{\circ} \times 1^{\circ}$ thermal model TC1 for the continental lithosphere: implications for lithosphere secular evolution. Tectonophysics 416:245-277. doi:10.1016/j.tecto.2005.11.022

Artemieva IM, Mooney WD (2001) Thermal structure and evolution of Precambrian lithosphere: a global study. J Geophys Res 106:16,387-16,414

Babuska V, Cara M (1991) Seismic anisotropy in the earth. Kluwer Academic Press, Boston

Baer M, Zweifel P, Giardini D (2000) The Swiss digital seismic network (SD-197 SNet). Orfeus Newsl 2 (2): $1-5$ 
Bassin C, Laske G, Masters G (2000) The current limits of resolution for surface wave tomography in North America. EOS Trans Am Geophys Union 81:F897

Becker TW, Boschi L (2002) A comparison of tomographic and geodynamic mantle models. Geochem Geophys Geosyst 3:2001GC000168

Bijwaard H, Spakman W, Engdahl ER (1998) Closing the gap between regional and global travel-time tomography. J Geophys Res 103:30,055-30,078

Boschi L (2003) Measures of resolution in global body-wave tomography. Geophys Res Lett 30:2003 GL018222

Boschi L (2006) Global multi-resolution models of surface wave propagation: comparing equivalentlyregularized Born- and Ray-theoretical solutions. Geophys J Int 167:238-252. doi:10.1111/j.1365246X.2006.03084.x

Boschi L, Dziewoński AM (1999) "High" and "low" resolution images of the Earth's mantle: implications of different approaches to tomographic modeling. J Geophys Res 104:25,567-25,594

Boschi L, Ekström G (2002) New images of the Earth's upper mantle from measurements of surface-wave phase velocity anomalies. J Geophys Res 107:2059. doi:10.129/2000JB000059

Boschi L, Ekström G, Kustowski B (2004) Multiple resolution surface wave tomography: the Mediterranean basin. Geophys J Int 157:293-304. doi:10.1111/j.1365-246X.2004.02194.X

Capitanio FA, Goes S (2006) Mesozoic spreading kinematics: consequences for Cenozoic Central and Western Mediterranean subduction. Geophys J Int 165:804-816. doi:10.1111/j.1365-246X.2006. 02892.x

Dahlen FA, Hung S-H, Nolet G (2000). Fréchet kernels for finite-frequency traveltimes-I. Theory. Geophys J Int 141:157-174

de Jonge MR, Wortel MJR, Spakman W (1994) Regional scale tectonic evolution and the seismic velocity structure of the lithosphere and upper mantle: the Mediterranean region. J Geophys Res 99:12,09112,108

Dercourt J, Zonenshain LP, Ricou L-E, Kazmin VG, Le Pichon X, Knipper AL, Grandjacquet C, Sbortshikov IM, Geyssant J, Lepvrier C, Pechersky DH, Boulin J, Sibuet J-C, Savostin LA, Sorokhtin O, Westphal M, Bazhenov ML, Lauer JP, Biju-Duval B (1986) Geological evolution of the Tethys from the Atlantic to the Pamirs since the Lias. Tectonophysics 123:241-315

Dziewoński AM, Anderson DL (1981) Preliminary reference Earth model. Phys Earth Planet Int 25:297-356

Ekström G, Dziewoński AM (1998) The unique anisotropy of the Pacific upper mantle. Nature 394:168-172

Ekström G, Tromp J, Larson EWF (1997) Measurements and global models of surface wave propagation. J Geophys Res 102:8137-8157

Faccenna C, Jolivet L, Piromallo C, Morelli A (2003) Subduction and the depth of convection in the Mediterranean mantle. J Geophys Res 108:2099. doi:10.1029/2001JB001690

Fan G, Wallace TC, Zhao D (1998) Tomographic imaging of deep velocity structure beneath the Eastern and Southern Carpathians, Romania: implications for continental collision. J Geophys Res 103:2705-2723

Fry B (2007) Surface wave tomography of the Mediterranean and central Europe: a new shear wave velocity model. Ph.D. Thesis, ETH Zürich, Switzerland

Fry B, Boschi L, Ekström G, Giardini D (2008) Europe-Mediterranean tomography: high correlation between new seismic data and independent geophysical observables. Geophys Res Lett 35:L04301. doi:10.1029/2007GL031519

Hansen PC (1992) Analysis of discrete ill-posed problems by means of the L-curve. SIAM Rev 34:561-580

Henger M, Berckhemer H, Seidl D (2002) The history of the development of the German Regional Seismic Network. In Korn M (ed) Ten years of German Regional Seismic Network (GRSN). Report 25 of the Senate Commission for Geoscience (DFG), Wiley-VCH, Weinheim, Germany, pp 1-8

Kirby JF, Swain CJ (2008) An accuracy assessment of the fan wavelet method for elastic thickness estimation. Geochem Geophys Geosyst 9:Q03022. doi:10.1029/2007GC001773

Kustowski B, Ekström G, Dziewoński AM (2008a) The shear-wave velocity structure in the upper mantle beneath Eurasia. Geophys J Int 174:978-992. doi:10.1111/j.1365-246X.2008.03865.x

Kustowski B, Ekström G, Dziewoński AM (2008b) Anisotropic shear-wave velocity structure of the Earth's mantle: a global model. J Geophys Res 113:B06306. doi:10.1029/2007JB005169

Lebedev S, van der Hilst RD (2008) Global upper-mantle tomography with the automated multimode inversion of surface and $S$-wave forms. Geophys J Int 173:505-518. doi:10.1111/j.1365-246X.2008. 03721.x

Li X-D, Romanowicz B (1996) Global mantle shear-velocity model developed using nonlinear asymptotic coupling theory. J Geophys Res 101:22,245-22,272

Lippitsch R, Kissling E, Ansorge J (2003) Upper mantle structure beneath the Alpine orogen from highresolution teleseismic tomography. J Geophys Res 108:2376. doi:10.1029/2002JB002016 
Marchant RH, Stampfli GM (1997) Subduction of continental crust in the Western Alps. Tectonophysics 269:217-235. doi:10.1016/S0040-1951(96)00170-9)

Marone F, van der Lee S, Giardini D (2004) Three-dimensional upper-mantle S velocity model for the Eurasia-Africa plate boundary region. Geophys J Int 158:109-130

Mooney WD, Laske G, Masters G (1998) CRUST-5.1: a global crustal model at $5^{\circ} \times 5^{\circ}$. J Geophys Res 103:727-747

Pérez-Gussinyé M, Watts AB (2005) The long-term strength of Europe and its implications for plate forming processes. Nature 381-384. doi:10.1038/nature03854

Pérez-Gussinyé M, Swain CJ, Kirby JF, Lowry T (2009) Spatial variations of the effective elastic thickness, $T_{e}$, using multitaper spectral estimation and wavelet methods: examples from synthetic data and application to South America. Geochem Geophys Geosyst (submitted)

Peter D, Boschi L, Deschamps F, Fry B, Ekström G, Giardini D (2008) Surface-wave tomography: finitefrequency shear-velocity inversions for the European-Mediterranean region. Geophys Res Lett 35:L16315. doi:10.1029/2008GL034769

Peter D, Boschi L, Woodhouse JH (2009) Tomographic resolution of ray and finite-frequency theories: a membrane-wave investigation. Geophys J Int (in press)

Pilidou S, Priestley K, Debayle E, Gudmundsson Ó (2005) Rayleigh wave tomography in the North Atlantic: high resolution images of the Iceland, Azores and Eifel mantle plumes. Lithos 79:453-474. doi: 10.1016/j.lithos.2004.09.012

Piromallo C, Morelli A (2003). P-wave tomography of the mantle under the Alpine-Mediterranean area. J Geophys Res 108. doi:10.1029/2002JB001757

Ritsema J, van Heijst HJ, Woodhouse JH (2004) Global transition zone tomography. J Geophys Res 109. doi:10.1029/2003JB002610

Schivardi R, Morelli A (2009) Surface wave tomography in the European and Mediterranean region. Geophys J Int (in press)

Schmid C, van der Lee S, VanDecar JC, Engdahl ER, Giardini D (2008) Three-dimensional $S$ velocity of the mantle in the Africa-Eurasia plate boundary region from phase arrival times and regional waveforms. J Geophys Res 113:B03306. doi:10.1029/2005JB004193

Simmons NA, Forte AM, Grand SP (2006) Constraining mantle flow with seismic and geodynamic data: a joint approach. Earth Planet Sci Lett 246:109-124

Spetzler J, Trampert J, Snieder R (2001) Are we exceeding the limits of the great circle approximation in surface wave tomography? Geophys Res Lett 28:2341-2344

Stehly L, Fry B, Campillo M, Shapiro N, Guilbert J, Boschi L, Giardini D (2009) Tomography of the Alpine region from observations of seismic ambient noise. Geophys J Int (in press)

Tesauro M, Kaban MK, Cloetingh SAPL (2008) EuCRUST-07: a new reference model for the European crust. Geophys Res Lett 35:L05313. doi:10.1029/2007GL032244

Trefethen LN, Bau D III (1997) Numerical linear algebra. Society for Industrial and Applied Mathematics, Philadelphia

Tromp J, Dahlen FA (1992) Variational principles for surface wave propagation on a laterally heterogeneous Earth-II. Frequency-domain JWKB theory. Geophys J Int 109:599-619

van der Lee S, Marone F, van der Meijde M, Giardini D, Deschamps A, Margheriti L, Burkett P, Solomon SC, Alves PM, Chouliaras M, Eshwehdi A, Suleiman A, Gashut H, Herak M, Ortiz R, Martin Davila J, Ugalde A, Vila J, Yelles K (2001) Eurasia-Africa plate boundary region yields new seismographic data. Eos Trans AGU 82(Fall Meet Suppl):637

Wang Z, Dahlen FA (1995) Global and regional structures inferred from surface waves. Geophys Res Lett 22:3099-3102

Weidle C, Maupin V (2008) An upper-mantle $S$-wave velocity model for Northern Europe from Love and Rayleigh group velocities. Geophys J Int 175:1154-1168. doi:10.1111/j.1365-246X.2008.03957.x

Wessel P, Smith WHF (1991) Free software helps map and display data. EOS Trans AGU 72:445-446

Wortel MJR, Spakman W (2000) Subduction and slab detachment in the Mediterranean-Carpathian region. Science 290:1910-1917. doi:10.1126/science.290.5498.1910

Zhou Y, Nolet G, Dahlen FA, Laske G (2006) Global upper-mantle structure from finite-frequency surfacewave tomography. J Geophys Res 111:B04304. doi:10.1029/2005JB003677 